Article

\title{
Retrieval and Validation of Cloud Top Temperature from the Geostationary Satellite INSAT-3D
}

\author{
Chaluparambil B. Lima ${ }^{1}$, Sudhakaran S. Prijith ${ }^{1}$, Mullapudi V. R. Sesha Sai ${ }^{1}$, \\ Pamaraju V. N. Rao ${ }^{1}$, Kandula Niranjan ${ }^{2}$ and Muvva V. Ramana ${ }^{1, *}$ \\ 1 National Remote Sensing Centre, Indian Space Research Organisation, Hyderabad PIN-500037, \\ Telangana State, India; limabalan05@gmail.com (C.B.L.); prijith_ss@nrsc.gov.in (S.S.P.); \\ seshasai_mvr@nrsc.gov.in (M.V.R.S.S.); rao_pvn@nrsc.gov.in (P.V.N.R.) \\ 2 Department of Physics, Andhra University, Visakhapatnam PIN-530003, Andhra Pradesh, India; \\ niranjankandula@hotmail.com \\ * Correspondence: ramana_mv@nrsc.gov.in; Tel.: +91-8542-225430
}

Received: 6 September 2019; Accepted: 7 November 2019; Published: 27 November 2019

\begin{abstract}
Investigation of cloud top temperature (CTT) and its diurnal variation is highly reliant on high spatial and temporal resolution satellite data, which is lacking over the Indian region. An algorithm has been developed for detection of clouds and retrieval of CTT from the geostationary satellite INSAT-3D. These retrievals are validated (inter-compared) with collocated in-situ (satellite) measurements with specific intent to generate climate-quality data. The cloud detection algorithm employs nine different tests, in accordance with solar illumination, satellite angle and surface type conditions to generate pixel-resolution cloud mask. Validation of cloud mask with cloud-aerosol lidar with orthogonal polarization (CALIOP) shows that probability of detection (POD) of cloudy (clear) sky is $81 \%(85 \%)$, with $83 \%$ hit rate. The algorithm is also implemented on similar channels of moderate resolution imaging spectroradiometer (MODIS), which provides $88 \%$ (83\%) POD of cloudy (clear) sky, with $86 \%$ hit rate. CTT retrieval is done at the pixel level, for all cloud pixels, by employing appropriate methods for various types of clouds. Comparison of CTT with radiosonde and cloud-aerosol lidar and infrared pathfinder satellite observations (CALIPSO) shows mean absolute error less than 3\%. The study also examines sensitivity of retrieved CTT to the cloud classification scheme and retrieval criteria. Validation results and their close agreements with those of similar satellites demonstrate the reliability of the retrieved product for climate studies.
\end{abstract}

Keywords: cloud detection; cloud top temperature; essential climate variable; INSAT-3D; inter-comparison; validation

\section{Introduction}

Clouds play a vital role in determining and governing weather and climate as they influence solar and terrestrial radiative transfer in the earth-atmosphere system, which makes cloud properties an essential climate variable [1,2]. In general, spatial coverage and optical thickness of clouds influence the radiative transfer and together with cloud top temperature (CTT) determine the thermal effect [3]. Contribution of optically thick low level clouds to net radiative forcing is, usually, strongly towards negative due to large short-wave radiative forcing (as reflection of solar radiation dominates trapping of terrestrial radiation), whereas that of high level clouds can be positive or negative (depending upon the distribution of ice water path) due to large long-wave radiative forcing [4-9]. However, radiative forcing due to cumulonimbus clouds is reported to be more or less neutral $[10,11]$. Thus, CTT is a crucial parameter in estimating short-wave and long-wave radiative effects of clouds, by confidently classifying clouds into different categories. A small change in abundance and distribution of clouds 
could change climate more than the anticipated changes caused by other factors associated with global change [12-14]. Radiative impacts of different types of clouds vary, depending on their properties and hence accurate representation of clouds in climate models is essential for realistic simulations of Earth's current and future climate $[15,16]$. Thus, continuous and detailed monitoring of cloud properties is necessary to realistically represent them in models to understand the role of clouds in the weather and climate system, apart from their inevitability in other applications such as nowcasting.

In addition, monitoring of cloud properties such as cloud cover and CTT is critical to examine the aerosol-cloud interaction, which is a major source of uncertainty in radiative forcing estimates [17]. Satellite data analysis revealed strong correlations between cloud cover and aerosols globally [18-21], whereas some studies showed decrease in cloud cover at high aerosol optical depths in regions of strong aerosol absorption [22]. Cloud top height (cloud top pressure/temperature) is also reported to be increasing (decreasing) globally with increase of aerosol optical depth [23-25], which leads to the invigorating convection hypothesis [23,26-30]. However, Niu and Li [31] showed that CTT is negatively correlated with aerosol optical depth over land (aerosol index over the ocean) for deep mixed-phase clouds with warm bases (with liquid droplets) and cold tops (with ice crystals), but not for completely liquid clouds. Massie et al. [32] have quantified aerosol indirect effect as a function of cloud top pressure over India using moderate resolution imaging spectroradiometer (MODIS) data and reported that the aerosol indirect effects are apparent for pressure levels associated with liquid droplets, but not for those associated with tropospheric ice crystals. In order to examine the aerosol-cloud interaction and associated processes, it is necessary to have concurrent measurements of aerosols and cloud properties at sufficient temporal resolution and spatial coverage. Moreover, continuous measurements of cloud parameters are necessary to validate climate models and improve climate change assessments by alleviating the uncertainties associated with the aerosol-cloud interaction.

Surface-based observations of cloud parameters over India and surrounding regions are relatively sparse. The reliability of the International Satellite Cloud Climatology Project (ISCCP) data over India and Indian Ocean is affected by lack of continuous satellite measurements [33]. Observations from polar orbiting satellites (example: advanced very high resolution radiometer (AVHRR), MODIS, etc.) are available at poor temporal resolution (twice daily) over tropical latitudes. Shang et al. [34] have shown inadequacy of this temporal resolution of twice per day of polar orbiting satellites to represent cloud variability and properties. Incomplete diurnal sampling causes strong discontinuities in the ISCCP products and introduces systematic errors in cloud properties [33]. Moreover, large heterogeneity and dynamic nature of clouds over India and surrounding regions make it necessary to have continuous observations over large spatial domain. This can be achieved only by retrieving cloud parameters using geostationary satellites, which provide measurements over large domain continuously.

Over the Indian sub-continental region, continuous monitoring of clouds from geostationary platform was initiated by the launch of KALPANA-1 in September, 2002. Very high resolution radiometer (VHRR), on-board KALPANA-1, provided radiance/brightness temperature (BT) at three channels: visible $(0.55-0.75 \mu \mathrm{m})$, water vapor $(5.7-7.1 \mu \mathrm{m})$ and thermal infrared $(10.5-12.5 \mu \mathrm{m})$ at $30 \mathrm{~min}$ temporal resolution with $2 \mathrm{~km}$ spatial resolution for visible and $8 \mathrm{~km}$ for water vapor and thermal infrared channels. However, limited number of channels of KALPANA-1 VHRR limits accuracy of retrieval of cloud parameters such as CTT, especially of partial clouds. INSAT-3D (INSAT-3DR), launched in 2013 (2016), carries an advanced version of VHRR (known as Imager) with more number of channels and better spatial resolution (see data Section 2). Additional channels of INSAT-3D (mid-wave infrared channel and extra channel in IR window) provide improved cloud detection, better identification of thin clouds and more accurate retrieval of CTT over the Indian region. Methods for CTT retrieval basically rely on cloud optical properties and hence proper classification of clouds is critical. For optically thick clouds, satellite measured brightness temperature at thermal infrared channel (10.3-11.3 $\mu \mathrm{m})$ can be considered as CTT, however, for semi-transparent and partial clouds, satellite measured brightness temperatures are contaminated by the transmitted radiation from underlying 
surfaces. More number of channels in INSAT-3D Imager facilitates better classification of clouds and hence accurate retrieval of CTT.

In the present study, an algorithm has been developed based on the available channels of INSAT-3D for detection of cloud pixels and retrieval of CTT. In order to provide weather and climate researchers more confidence on quality of these retrievals, validation (comparison) of the products are carried out and uncertainties are estimated with in-situ (satellite) measurements. Implementation of the present algorithm on both INSAT-3D and 3DR will provide cloud mask and CTT at an interval of $15 \mathrm{~min}$ (as the former provides observations at HH:00, HH:30 and the latter does at HH:15 and HH:45, where HH represents hour) over the Indian region. Generation of long term database of CTT at this finer interval would improve the representation of cloud properties and their diurnal variations in model simulations.

\section{Data}

Imager onboard the Indian geostationary satellite, INSAT-3D provides observations over the Indian region at a temporal interval of $30 \mathrm{~min}$ (at HH:00 and HH:30) with visible (VIS), short-wave infrared (SWIR), mid-wave infrared (MIR), water vapor (WV) and thermal infrared (TIR1 and TIR2) channels [35]. Specifications of these channels are given in Table 1. Present study uses level 1C, Asia sector product (ASIA_MER_L1C) from INSAT-3D Imager over India and surrounding regions bounded by $44.5^{\circ} \mathrm{E}-105.5^{\circ} \mathrm{E}$ and $10^{\circ} \mathrm{S}-45.5^{\circ} \mathrm{N}$ with spatial resolution of $4 \mathrm{~km}$, which is available through the ISRO web portal, MOSDAC (https://www.mosdac.gov.in). The present study makes use of VIS, MIR, WV, TIR1 and TIR2 channels to identify cloud pixels and retrieve CTT for the period of September, 2014 to February, 2017. Spatial resolutions of VIS and WV channels are $1 \mathrm{~km}$ and $8 \mathrm{~km}$ respectively, whereas those of MIR and TIR channels are $4 \mathrm{~km}$. In order to maintain uniformity, measurements from VIS and WV channels are also provided at $4 \mathrm{~km}$ spatial resolution to match with that of MIR and TIR channels.

Table 1. Specifications of INSAT-3D Imager channels.

\begin{tabular}{cccc}
\hline Channels & $\begin{array}{c}\text { Spectral Range } \\
(\mu \mathbf{m})\end{array}$ & $\begin{array}{c}\text { Central Wavelength } \\
(\mu \mathbf{m})\end{array}$ & $\begin{array}{c}\text { Resolution } \\
(\mathbf{k m})\end{array}$ \\
\hline Visible (VIS) & $0.55-0.75$ & 0.65 & 1.0 \\
\hline $\begin{array}{c}\text { Short-wave Infrared } \\
(\text { SWIR) }\end{array}$ & $1.55-1.70$ & 1.62 & 1.0 \\
\hline $\begin{array}{c}\text { Mid-wave Infrared } \\
(\text { MIR) }\end{array}$ & $3.80-4.00$ & 3.9 & 4.0 \\
\hline Water Vapor (WV) & $6.50-7.10$ & 6.8 & 8.0 \\
\hline Thermal Infrared I (TIR1) & $10.3-11.3$ & 10.8 & 4.0 \\
\hline $\begin{array}{c}\text { Thermal Infrared II } \\
(\text { TIR2 })\end{array}$ & $11.5-12.5$ & 12.0 & 4.0 \\
\hline
\end{tabular}

Performance of cloud detection scheme employed in the algorithm has been examined by comparing the cloud mask, generated by implementing the same on INSAT-3D, with cloud products from the active space borne sensor, cloud-aerosol lidar with orthogonal polarization (CALIOP) and the passive sensor, MODIS. CALIOP onboard cloud-aerosol lidar and infrared pathfinder satellite observations (CALIPSO) provides measurements of clouds with the LIDAR operating at $532 \mathrm{~nm}$ and $1064 \mathrm{~nm}$ [36]. CALIOP retrieved cloud products are widely used for examining distribution of clouds and also for verifying new cloud detection algorithms [37-41]. CALIOP provides information on vertical distribution of clouds with along-track spatial interval of $333 \mathrm{~m}$ on earth's surface, with a foot print of $70 \mathrm{~m}$ diameter. Level-2 CALIPSO cloud layer products (version 4) are used in this study. Since CALIPSO and INSAT-3D operate under different sampling schemes, only those INSAT-3D pixels within which all CALIPSO measurements are cloudy (or clear) with cloud aerosol discrimination 
(CAD) score of 70-100 are retained for the comparison purpose. Basically, CAD score indicates a numerical confidence level for CALIOP classification of features into clouds and aerosols [42]. Smaller positive values of CAD score indicate less confidence on feature classification into clouds, whereas value of 100 shows complete confidence. Thus, the CAD score of 70-100 ensures high confidence on CALIOP identified cloud pixels and those pixels are used for comparison. INSAT-3D retrieved CTT is also inter-compared with layer top temperature of topmost cloud layer from CALIPSO. Fundamental data from CALIOP is the vertical position (altitude) of clouds. Conversion of cloud top height (CTH) to CTT in version 4 cloud layer products of CALIPSO uses the Modern-Era Retrospective Analysis for Research and Applications, Version 2 (MERRA-2) dataset [43,44].

MODIS, onboard the satellites Terra and Aqua, provides measurements at 36 spectral channels in visible and IR regions [45,46]. Collection 6.1 level 2 cloud product (MYD06_L2) at a spatial resolution of $5 \mathrm{~km}$ from MODIS onboard Aqua is used in the present study for the comparison. The data product contains cloud mask generated over different surface types including land, water, snow/ice, desert and coast for both day and night $[47,48]$. The dataset provides cloud mask with four levels of confidence; (i) confident clear, (ii) probably clear, (iii) uncertain/probably cloudy and (iv) cloudy.

In addition, climatology of the monthly sea surface temperature (SST) at $4 \mathrm{~km}$ spatial resolution for both day and night, during February 2000 to December 2015, from MODIS onboard Terra is used to fix SST thresholds in one of the tests used in cloud detection scheme of the algorithm. The present algorithm uses day time climatological monthly SST for cloud detection during day time/twilight and night time climatological monthly SST for cloud detection during night time. The study also uses global digital elevation model data (GTOPO30) at 30 arc second $(\sim 1 \mathrm{~km})$ horizontal resolution to incorporate continental topographic features in one of the tests employed to detect clouds over land regions. In order to use this data set, it is re-gridded to $4 \mathrm{~km} \times 4 \mathrm{~km}$ spatial resolution to match with that of INSAT-3D data.

Validation of retrieved CTT from INSAT-3D, by employing the present algorithm, is carried out by comparing the same with CTT estimates using radiosonde measurements. Radiosonde data during September, 2014-December, 2016 from SHAR/ISRO Sriharikota $\left(13.7^{\circ} \mathrm{N}\right.$ and $\left.80.2^{\circ} \mathrm{E}\right)$, the space port of India situated on the east coast of southern peninsula, are used for the validation. Vertical profiles of temperature, humidity and pressure from radiosonde measurements are used to identify cloud layers and further to obtain CTT. Large horizontal drift of radiosonde, even more than $100 \mathrm{~km}$, from launch location to top of topmost cloud layer; is seen in several cases. This issue is addressed using the GPS measurements along with the radiosondes. GPS measurements allow the exact collocation of cloud top from radiosonde with that from INSAT-3D for the validation.

\section{Methods}

Accurate identification of cloud pixels from satellite imagery is fundamental and critical for retrieval of any of the cloud properties. Any inaccuracy in determining cloud pixels will in turn cause uncertainties in retrieval of cloud properties. Hence the algorithm developed and employed in the present study has two parts: (i) cloud detection scheme and (ii) CTT retrieval scheme. The cloud detection is carried out by an integrated approach in which nine different tests are performed by grouping them into primary, secondary and semi-transparent cirrus (STC) identification tests. The primary test employs stringent criteria to avoid any misclassification of clear pixel as cloudy, which may lead to miss out of some cloud pixels. Such pixels are retrieved through a set of secondary tests. In order to minimize probability of misclassification through secondary tests, a pixel is identified as cloudy only if it is detected so by multiple secondary tests. STC clouds are detected by a combination of two different tests using BT at TIR1, TIR2 and WV channels. Threshold values used in the primary test are selected by considering possible variations of surface temperature over the study region during a period of time used in the test. Identified cloud pixels are subjected to CTT retrieval scheme, which categorizes cloud pixels into various cloud types (like opaque, semi-transparent cirrus and partial) and chooses suitable methods for the retrieval of CTT. For low level and high level opaque clouds, BT at 
TIR1 channel is considered as CTT. For STC and partial clouds, a method based on two dimensional scatter plot between BT at TIR1 and brightness temperature difference (BTD) of TIR1 and TIR2 is used for CTT retrieval. Performance of cloud detection and CTT retrieval algorithms is examined by comparing with ground based and satellite observations. The integrated approach employed in this study is first of its kind for the retrieval of CTT from the geostationary satellite, INSAT-3D with a specific intent to generate climate quality data.

\subsection{Cloud Detection Scheme: Algorithm Overview}

The detection scheme contains a series of hierarchical decision tree tests, which exploit differences in spectral signatures of clouds and underlying surfaces. Each pixel undergoes a subroutine that provides information of surface type (ocean and land) and solar illumination conditions (day, night, twilight and sunglint). Solar elevation angle $\left(\delta_{\text {Sun }}\right)$ is used to describe solar illumination conditions; where it is considered as day time when $\delta_{\text {Sun }}>10$, night when $\delta_{\text {Sun }}=0$ and twilight when $0<\delta_{\text {Sun }} \leq 10$ [49,50]. This classification is critical in defining proper thresholds for cloud detection, especially over the Indian region where surface characteristics are highly heterogeneous in nature with different geo-spatial features. The cloud detection algorithm involves three set of tests: a primary test (for all types of surfaces and solar illumination conditions), a combination of four (three) secondary tests during day/twilight (night) and a combination of two tests for identifying STC clouds. Successful performance of this cloud detection algorithm relies on the selection of proper thresholds for various spectral tests. The threshold values, which better suit to local atmospheric and surface conditions, used in this study are either generated or adopted from previous studies. The primary test uses different criteria for the thresholds over land and ocean and is, in general, capable of identifying most of the cloud pixels with very high confidence. Secondary tests are applied only on those pixels, which are not identified as cloudy by the primary test. In the secondary test, a pixel is considered as cloudy if it satisfies at least three (two) out of four (three) tests during day time/twilight (night time) conditions. Though primary and secondary tests are efficient enough to identify most of the clouds, these tests are observed to fall short in detecting STC clouds due to high transparency at visible and IR wavelengths. Hence, the present algorithm uses additional two tests for detecting STC clouds from the remaining pixels.

Algorithm for retrieval of clouds over ocean and land are detailed in the flowcharts given in Figures 1 and 2 respectively. Most of the tests are similar for ocean and land, but differ in terms of the thresholds applied. While the SST based threshold method is used for detecting cloud pixels over ocean, another test based on topography is employed over land. One of the major challenges in identifying cloud pixels over ocean arises due to specular reflection of intense solar radiation from sunglint areas, which leads to misclassification of clear pixels as cloudy.

A major challenge over land in the detection of clouds by satellites is due to high albedo surfaces, such as snow cover over Himalayas in the present study, due to their low BT in thermal and high reflectance in visible wavelengths as those of clouds. In order to identify snow covered pixels, a set of three tests, which uses day time BT from MIR (here after, $\mathrm{BT}_{\mathrm{MIR}}$ ), TIR1 (here after, $\mathrm{BT}_{\mathrm{TIR} 1}$ ) and TIR2 (here after, $\mathrm{BT}_{\mathrm{TIR} 2}$ ) channels, is used in the current algorithm [49]. If a pixel is identified as snow covered under day time conditions, it is considered to be so for night time and twilight conditions also and hence not considered for the cloud detection tests. 


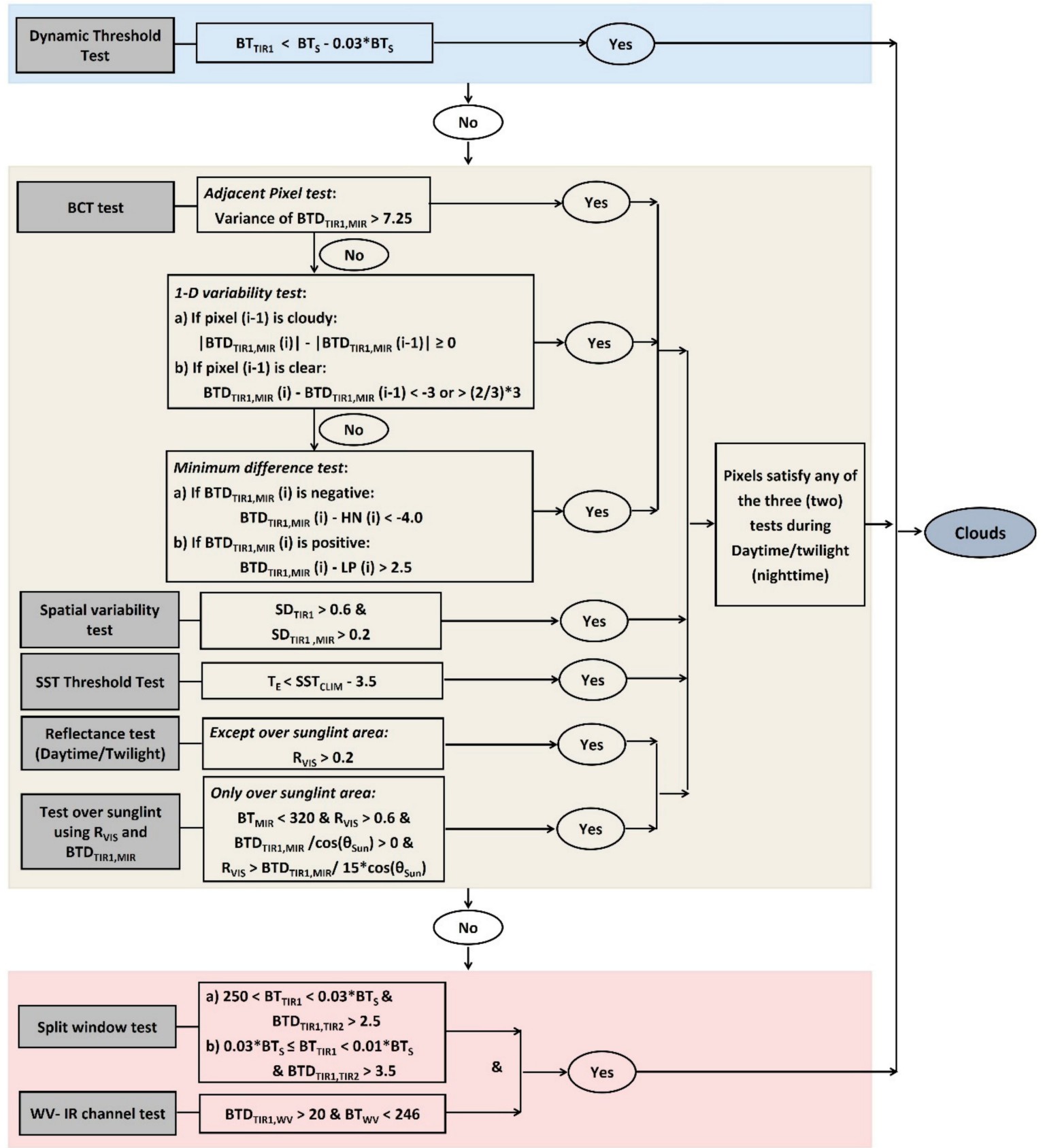

Figure 1. Flow chart depicting series of tests employed in the algorithm for cloud detection by INSAT-3D over ocean. 


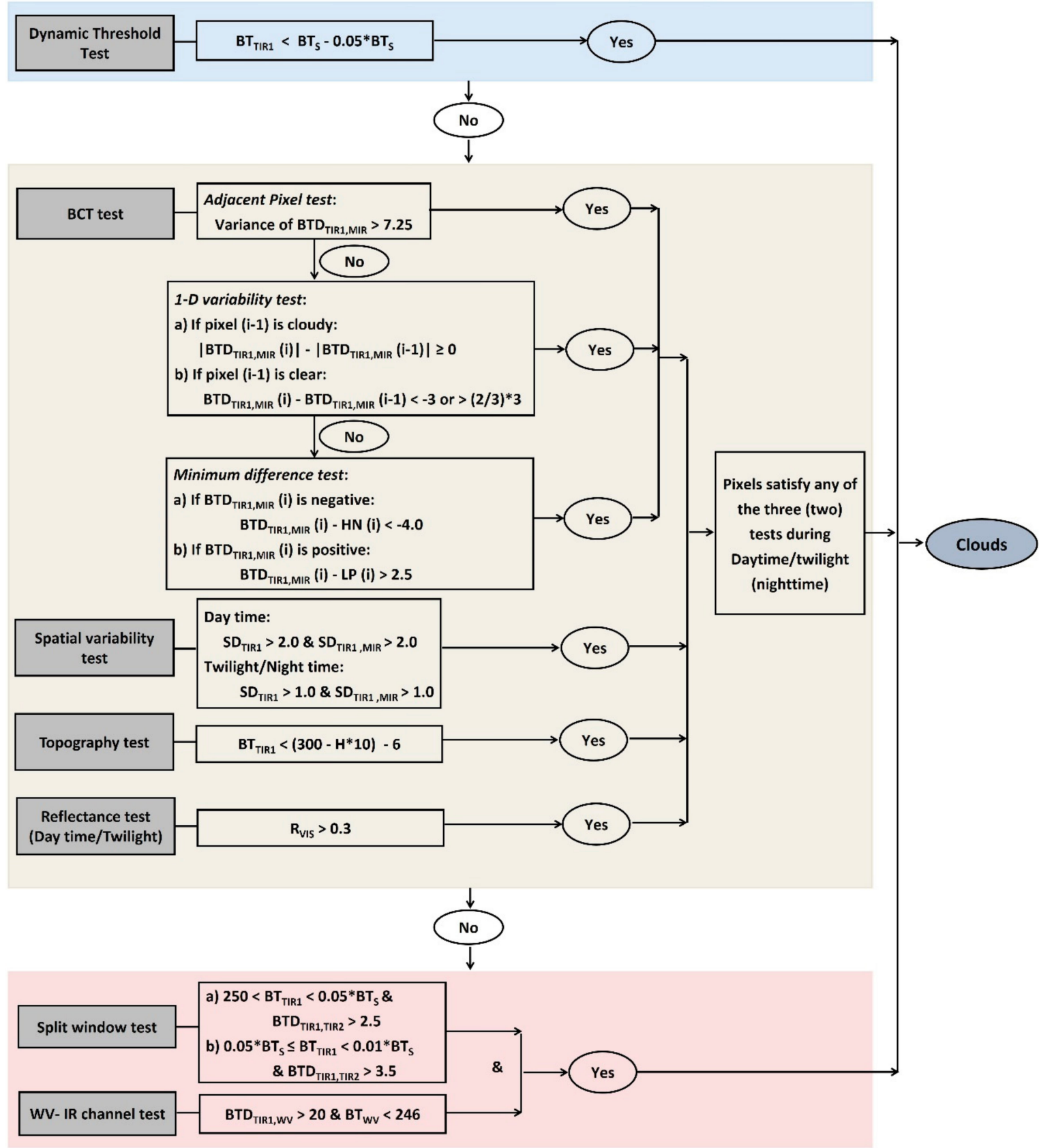

Figure 2. Flow chart depicting series of tests employed in the algorithm for cloud detection by INSAT-3D over land.

\subsubsection{Cloud identification tests in the algorithm}

\section{Primary Test: Dynamic Threshold Test}

A primary test, which uses dynamically varying threshold for $\mathrm{BT}_{\mathrm{TIR} 1}$, is employed on each individual INSAT-3D pixel to segregate cloud pixels with very high confidence. Several studies have used this test, by making use of the disparity in $\mathrm{BT}_{\mathrm{TIR} 1}$ between clouds and earth surfaces, with either static or dynamic thresholds for bulk cloud detection [47,51-53]. In order to obtain dynamic thresholds in the current algorithm, clear-sky BT corresponding to surface $\left(\mathrm{BT}_{\mathrm{S}}\right)$ for each pixel is estimated by taking the highest $\mathrm{BT}$ in the same pixel during previous 30 days, for the same local time of observation, assuming at least one clear sky condition during the period. The thresholds used in the present algorithm are assigned by considering possible variations of surface temperature over the study 
region for a period of 30 days, even during gradually advancing winter season. Figures S1 and S2 in Supplementary Materials show percentage decrease in two day mean SST and land surface temperature (LST), from MODIS onboard Terra and Aqua, during the days December 30-31, 2016, compared to those during December 1-2, 2016. Mean of two days is considered only to improve the data coverage. During this period of 30 days, decrease of LST (SST) is observed to be $1.6 \%(0.3 \%)$. Since, the primary test aims to identify cloud pixels with very high confidence; the present study implements threshold values higher than the possible variation of surface temperature. Thus, a pixel is flagged as cloudy if the satellite measured $\mathrm{BT}_{\mathrm{TIR} 1}$ is less than the corresponding $\mathrm{BT}_{\mathrm{S}}$ by more than $3 \%(5 \%)$ of $\mathrm{BT}_{\mathrm{S}}$ over ocean (land). Similarly, Rossow and Garder [53] have used a threshold of $6 \mathrm{~K}$ over land and $1 \mathrm{~K}$ over ocean, whereas Choi and Ho [51] have used $12 \mathrm{~K}$ and $3.5 \mathrm{~K}$ respectively. However, clouds persisting for long days, which are possible during summer monsoon time, may limit the performance of this test.

\section{Secondary Tests}

Since dynamical threshold values of $\mathrm{BT}_{\mathrm{TIR} 1}$ used in the primary test of the cloud detection scheme are to identify cloud pixels with very high confidence, some of the clouds such as low level warm clouds may not be detected by this test. In order to detect remaining clouds, a series of secondary tests is carried out on the pixels, which are not identified as cloudy by the primary test.

(a) Bi-spectral composite threshold (BCT) test:

The BCT test employed in the current algorithm makes use of the fact that emissivity of clouds is higher at longer wavelengths, compared to that at shorter wavelengths, which leads to higher values of $\mathrm{BT}_{\mathrm{TIR} 1}$ than $\mathrm{BT}_{\mathrm{MIR}}$ over cloud pixels [54]. The BCT composite test includes three different tests. The first test examines variance of BTD of TIR1 and MIR (i.e., $\mathrm{BT}_{\mathrm{TIR} 1}-\mathrm{BT}_{\mathrm{MIR}}$; denoted as $\mathrm{BTD}_{\mathrm{TIR} 1, \mathrm{MIR}}$ ) in each pixel (i), with respect to previous one (i-1), and identifies it as cloudy if the variance is more than the threshold, whereas the second test identifies cloud pixels by comparing BTD $_{\text {TIR1,MIR }}$ in each pixel with that in the previous one. The third test makes use of dynamical thresholds of BTD TIR1,MIR, by considering $\mathrm{BTD}_{\mathrm{TIR} 1, \mathrm{MIR}}$ values in each pixel for the past 30 days. If $\mathrm{BTD}_{\mathrm{TIR} 1, \mathrm{MIR}}$ is negative in a pixel, it is compared with the highest negative value of $B_{T D} D_{T I R 1, M I R}(H N)$ within the previous 30 days in that pixel, whereas the comparison is with the lowest positive value of $\mathrm{BTD}_{\mathrm{TIR} 1, \mathrm{MIR}}(\mathrm{LP})$ if $\mathrm{BTD}_{\mathrm{TIR} 1, \mathrm{MIR}}$ in a pixel is positive. The threshold values used in these tests are adopted from Jedlovec et al. [55] and are provided in the flowcharts.

(b) Spatial variability test:

Clouds exhibit large spatial variability of BT at IR channels, compared to underlying homogeneous surfaces and this fact is made use of in cloud detection schemes to delineate cloud pixels [56]. In addition, spatial variability of $\mathrm{BTD}_{\mathrm{TIR} 1, \mathrm{MIR}}$ is also reported to be more over clouds [49]. In the present algorithm, spatial variability of $\mathrm{BT}_{\mathrm{TIR} 1}$ and $\mathrm{BTD}_{\mathrm{TIR} 1, \mathrm{MIR}}$ are used to identify cloud pixels, by considering an area of $12 \mathrm{~km} \times 12 \mathrm{~km}$ surrounding the pixel. Over ocean, thresholds for standard deviation of $\mathrm{BT}_{\mathrm{TIR} 1}$ (i.e., $\mathrm{SD}_{\mathrm{TIR} 1}$ ) and $\mathrm{BTD}_{\mathrm{TIR} 1, \mathrm{MIR}}$ (i.e., $\mathrm{SD}_{\mathrm{TIR} 1, \mathrm{MIR}}$ ) are taken to be 0.6 and 0.2 respectively. However, land surfaces are more inhomogeneous in nature, which can lead to more spatial variability, and hence different thresholds are used for delineating cloud pixels over land under different solar illumination conditions [49].

(c) Sea surface temperature threshold test:

SST can be estimated using a non-linear split window technique with $\mathrm{BT}_{\mathrm{TIR} 1}$ and $\mathrm{BT}_{\mathrm{TIR} 2}$ measurements over cloud free pixels [57]. Same estimation of temperature $\left(T_{E}\right)$ on a cloud pixel will yield a lower temperature compared to actual SST. Taking advantage of this, detection of cloud pixels over ocean has been carried out by comparing the $\mathrm{T}_{\mathrm{E}}$ value in each pixel with monthly mean

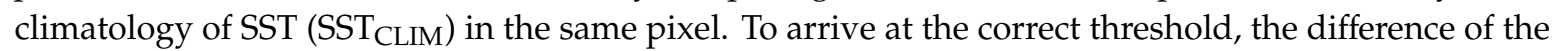
monthly mean SST $_{\text {CLIM }}$ between day time and night time from MODIS onboard Terra is examined. Figure S3 in Supplementary Materials shows day time and night time SST difference in each month during a period of 2000 to 2015, which is observed to be within 2 K. Possible variation of SST within day time (or night time) is considered to fix the criteria as $\mathrm{SST}_{\mathrm{CLIM}}-3.5 \mathrm{~K}$. This offset of $3.5 \mathrm{~K}$ is needed 
to account for the inadequacy of the climatology data, especially over the areas where SST variation is more in space and time (for example, over coastal areas). Thus, a pixel is classified as cloudy in the current algorithm, if $\mathrm{T}_{\mathrm{E}}$ is less than $\mathrm{SST}_{\mathrm{CLIM}}$ by at least $3.5 \mathrm{~K}$. Thus, the possible variation of SST within day time (or night time) would be very well below the threshold of $3.5 \mathrm{~K}$ used in the current algorithm and hence, even for the time of highest SST difference, the condition of SST CLIM $-3.5 \mathrm{~K}$ would not lead to any misclassification of clear sky pixel as cloudy.

(d) Topography test:

The primary test employed may fail to detect low level clouds over high elevation surfaces such as mountains, when the temperature difference between cloud top and surface is not large enough. Hence the topography test is used to identify clouds over such regions, by assuming a dry adiabatic lapse rate of $10 \mathrm{Kkm}^{-1}$ and mean sea level temperature of $300 \mathrm{~K}$. Thus the threshold for each pixel is estimated as $\mathrm{T}_{\mathrm{TT}}=300-(10 \times \mathrm{H})$, where $\mathrm{H}$ is the surface elevation above mean sea level in $\mathrm{km}$. A pixel is flagged as cloudy if the satellite measured $\mathrm{BT}_{\mathrm{TIR} 1}$ is less than $\mathrm{T}_{\mathrm{TT}}-6 \mathrm{~K}$. This offset of $6 \mathrm{~K}$ is arrived at, after carrying out a sensitivity analysis.

(e) Reflectance test:

Clouds show large reflectance at visible channels and hence this fact is made use of in detection of cloud pixels during day time. Pixels are identified as cloudy in the present algorithm, if reflectance at VIS channel is greater than 0.2 over ocean and 0.3 over land [58]. However, the reflectance test may lead to misclassification of highly reflecting surfaces as clouds and hence it is not applied over the pixels that are identified to be affected by sunglint. Another test is employed over sunglint areas, by considering reflectance at VIS ( $\left.\mathrm{R}_{\mathrm{VIS}}\right)$ and BT at MIR channels respectively along with sun-satellite geometry (see Figure 1). The test was proposed by Derrien and Gléau [49] and it relies on the fact that cloud reflectance decreases with increase of wavelength from VIS to MIR, whereas the reflectance over sunglint remains high at both the channels. Percentage probability $\left(P_{\text {sunglint }}\right)$ of sunglint is estimated from sun-satellite geometry [59] as:

$$
P_{\text {sunglint }}=\exp \left(-\frac{1}{2}\left(\frac{\theta}{8.5}\right)^{2}\right) \times 100 \%,
$$

where $\theta$ is the sum of the solar and satellite zenith angles. A threshold of $0.1 \%$ for $P_{\text {sunglint }}$ is set to indicate the areas with risk of sunglint and those pixels with $P_{\text {sunglint }}$ greater than $0.1 \%$ are considered as sunglint pixels [50].

\section{Detection of STC Clouds}

Transparency of high altitude thin cirrus clouds, at visible to infrared wavelengths [60], makes their detection difficult through passive satellite remote sensing techniques. Increase in transparency of clouds leads to transmittance of more radiation from surface to satellite and hence the estimated BT will be higher than the actual CTT. This leads to misclassification of STC clouds as low level warm clouds or even as clear sky conditions. The present algorithm employs two different tests for detecting STC clouds; (i) split window technique with $\mathrm{BT}_{\mathrm{TIR} 1}$ and $\mathrm{BTD}$ of TIR1 and TIR2 (i.e., $\mathrm{BT}_{\mathrm{TIR} 1}-\mathrm{BT}_{\mathrm{TIR} 2}$; denoted as BTD $_{\text {TIR1,TIR2 }}$ [61,62] and (ii) the WV-IR method using $\mathrm{BT}_{\mathrm{WV}}$ and BTD of TIR1 and WV channel (i.e., $\mathrm{BT}_{\mathrm{TIR} 1}-\mathrm{BT}_{\mathrm{WV}}$; denoted as $\left.\mathrm{BTD}_{\mathrm{TIR} 1, \mathrm{WV}}\right)[63,64]$. Threshold values for these tests are adopted from Inoue [61,62], Roca et al. [63] and Rajeev et al. [64]. Roca et al. [63] and Rajeev et al. [64] have established the threshold values for the same region in the present study. Thresholds used for identifying STC clouds with these two tests are provided in the flowcharts in Figures 1 and 2. A pixel is identified as a STC cloud, only if it is detected to be so by both of the tests.

\subsection{Retrieval of Cloud Top Temperature}

Satellite derived BT of clouds can differ from the actual CTT, depending on the emissivity of clouds and relative contribution of radiation from clouds and underlying surface. Hence different 
techniques need to be implemented for retrieval of CTT for different types of clouds. Thus, in the present algorithm, CTT retrieval is carried out after classifying the detected cloud pixels into four categories: low level opaque, high level opaque, STC and partial clouds. The classification is carried out using BT measurements at thermal and water vapor channels. Out of the detected cloud pixels, those satisfy any of the two conditions of STC clouds are segregated first. From the remaining cloud pixels, those with $\mathrm{BT}_{\mathrm{TIR} 1}<250 \mathrm{~K}$ and $0 \leq \mathrm{BTD}_{\mathrm{TIR} 1, \mathrm{TIR} 2} \leq 0.5$ are classified as high level opaque and those with $\mathrm{BT}_{\mathrm{TIR} 1} \geq 250 \mathrm{~K}$ and $0 \leq \mathrm{BTD}_{\mathrm{TIR} 1, \mathrm{TIR} 2} \leq 1$ are grouped as low level opaque clouds [51]. The cloud pixels, those do not fall in any of the above three categories are considered as partial clouds.

For opaque clouds, emissivity is assumed to be unity and hence $\mathrm{BT}_{\mathrm{TIR} 1}$ is considered as CTT. However, for STC and partial clouds, the amount of radiation reaching satellite is partly contributed by the cloud and partly by underneath surface. In such cases, effective emissivity of clouds is to be estimated to delineate both the contributions so that the CTT can be retrieved.

\subsubsection{Retrieval of Cloud Top Temperature of STC and Partial Clouds}

The CTT retrieval scheme employed for STC/partial clouds is based on two dimensional scatter plot between $\mathrm{BT}_{\mathrm{TIR} 1}$ and $\mathrm{BTD}_{\mathrm{TIR} 1, \mathrm{TIR} 2}$ over a region consisting of clear, opaque and STC/partial clouds $[61,65]$. The scatter plot provides an arc like structure with high $\mathrm{BT}_{\mathrm{TIR} 1}$ and low $\mathrm{BTD}_{\mathrm{TIR} 1, \mathrm{TIR} 2}$ corresponding to clear pixels, low $\mathrm{BT}_{\mathrm{TIR} 1}$ and low $\mathrm{BTD}_{\mathrm{TIR} 1, \mathrm{TIR} 2}$ to opaque clouds and high $\mathrm{BTD}_{\mathrm{TIR} 1, \mathrm{TIR} 2}$ with intermediate $\mathrm{BT}_{\mathrm{TIR} 1}$ to STC/partial clouds at same altitude of the opaque clouds. Thus, the right and left sides of the curve represent clear pixels and opaque clouds respectively, whereas the middle part represents STC/partial clouds. Detailed description of the methodology is given in Korpela et al. [66].

The current CTT retrieval algorithm considers an area of 15 pixels $\times 15$ pixels surrounding a pixel of STC/ partial cloud and fits the arc like curve between $\mathrm{BT}_{\mathrm{TIR} 1}$ and $\mathrm{BTD}_{\mathrm{TIR} 1, \mathrm{TIR} 2}$, by using the non-linear relation given below [66]:

$$
\operatorname{BTD}_{\text {est }(x, p)}=\left(\left[\frac{x-T_{\mathcal{C}}}{T_{S, T I R 1}-T_{\mathcal{c}}}\right]-\left[\frac{x-T_{\mathcal{C}}}{T_{S, T I R 1}-T_{\mathcal{c}}}\right]^{\beta}\right)\left(T_{S, T I R 1}-T_{\mathcal{c}}\right)+\left[\frac{x-T_{\mathcal{C}}}{T_{S, T I R 1}-T_{\mathcal{c}}}\right]^{\beta}\left(\operatorname{BTD}_{S, T I R 1, T I R 2}\right),
$$

where, $x$ is satellite measured $\mathrm{BT}_{\mathrm{TIR} 1}, B T D_{\text {est }}$ is the estimated difference in brightness temperature between TIR1 and TIR2 and $p$ is a function of four parameters; cloud top temperature $\left(T_{c}\right)$, ratio of absorption coefficient of TIR2 and TIR1 $(\beta)$, surface temperature at TIR1 (TS,TIR1) and difference of surface temperature at TIR1 and TIR2 $\left(B T D_{S, T I R 1, T I R 2}\right)$, which are free to adjust so that the best fit of observation can be obtained. An iterative method is used, which tries to find the best fit through iterative adjustments in two of the free parameters $T_{\mathcal{c}}$ and $\beta$. Other parameters $T_{S, T I R 1}$ and $B T D_{S, T I R 1, T I R 2}$ are fixed from the measurements. $T_{S, T I R 1}$ is the highest $\mathrm{BT}_{\mathrm{TIR} 1}$ of clear sky pixels within the selected region if clear sky pixels are present within it. If there is no clear sky pixel available in the selected region, $\mathrm{BT}_{\mathrm{TIR} 1}$ of nearest clear sky pixel is considered as $T_{S, T I R 1}$. Similarly, BTD $D_{S, T I R 1, T I R 2}$ is the minimum of $B D_{\text {TIR1,TIR2 }}$ among the clear sky pixels, if they are available within the region or else the BTD $_{\text {TIR1,TIR2 }}$ corresponding to nearest clear sky pixel. Iterations are done by varying the value of $T_{c}$ from $180 \mathrm{~K}$ to $\mathrm{BT}_{\mathrm{TIR} 1}$ in the pixel, at an interval of $0.5 \mathrm{~K}$, with values of $\beta$ ranging from 1 to 2 at an interval of 0.1 . The best fit is identified as the one with minimum root mean square value between estimated and satellite measured BTD and the corresponding $T_{c}$ value is considered as the CTT.

Efficiency of this method depends on the availability of sufficient number of clear, cloudy and STC/partial pixels within the region of consideration. In the present algorithm, CTT retrieval of STC/partial clouds is carried out, with full confidence, if at least one pixel is available in all the three categories; opaque, clear and STC/partial. The remaining cases are considered for retrieval, if at least 25 cloud pixels are available, but flagged with low confidence. 


\subsection{Cloud Mask from CALIPSO and MODIS for Validation}

In order to ensure accurate evaluation of generated cloud mask by implementing the present algorithm on INSAT-3D, collocated reference datasets are carefully prepared from CALIOP and MODIS. From CALIPSO $5 \mathrm{~km}$ cloud layer dataset, clear and cloud pixels for inter-comparison are identified by using feature classification flags at different atmospheric layers and their quality assessment. Accuracy of clear and cloud features from CALIOP is ensured by considering only those pixels with quality assessment (QA) value high (high value of $\mathrm{QA}$ is same as the CAD score $\geq 70$ ) [67]. Due to the multiple averaging resolution scheme adopted in the CALIOP product retrieval algorithm, the $5 \mathrm{~km}$ layer product includes layers with fundamental horizontal averaging distance of $5 \mathrm{~km}$, an intermediate distance of $20 \mathrm{~km}$ and a maximum of $80 \mathrm{~km} \mathrm{[36].} \mathrm{This} \mathrm{leads} \mathrm{to} \mathrm{an} \mathrm{overlap} \mathrm{of} \mathrm{features} \mathrm{in} \mathrm{vertical}$ dimensions in the CALIOP data and such overlapping is avoided by considering only pixels with horizontal averaging of $5 \mathrm{~km}$. After segregating highly confident clear and cloud pixels at each layer from CALIOP, a binary cloud mask is generated in which cloud pixels are those with at least one layer of confident cloud feature and clear pixels are those with all layers of clear feature. From the level 2 MODIS cloud product, only those pixels, which are classified as either confident clear or cloudy are considered for comparison in the present study. However, in order to perform inter-comparisons, collocated pixels are identified among INSAT-3D, MODIS and CALIOP by using the nearest neighbor approach with a maximum distance of $500 \mathrm{~m}$ separation between centers of the pixels, within $\pm 30 \mathrm{~min}$ temporal difference.

\subsection{Implementation of INSAT-3D Algorithm on MODIS Channels}

The developed cloud detection algorithm for INSAT-3D is applied on the radiance/reflectance data from comparable channels of MODIS. MODIS channels considered here are having central wavelengths at $0.645 \mu \mathrm{m}, 3.9 \mu \mathrm{m}, 6.715 \mu \mathrm{m}, 11.03 \mu \mathrm{m}$ and $12.02 \mu \mathrm{m}$, which are close to the VIS, MIR, WV, TIR1 and TIR2 channels of INSAT-3D respectively. Basically, MODIS provides reflectance at visible and radiance at remaining channels. In order to implement the present cloud detection algorithm on MODIS channels, radiances of all channels except $0.645 \mu \mathrm{m}$ channel are converted to BT using Planck's equation. Other datasets used in the cloud detection algorithm, such as SST climatology and GTOPO30, are re-gridded to the spatial resolution of MODIS data. Finally, all tests in the present cloud detection algorithm (see Section 3.1) are applied to MODIS channels, as they are implemented on INSAT-3D channels. The cloud mask thus generated, by implementing the algorithm on MODIS channels, is validated using reference dataset from CALIOP and MODIS (detailed in Section 3.3).

\subsection{Cloud Classes and CTT from CALIOP}

Identified cloud pixels from INSAT-3D are grouped into four categories and they are compared with confident cloud pixels from CALIOP, which are identified as detailed in Section 3.3. Identified single layer cloud pixels from CALIOP are categorized into two classes: thick and thin, based on a pre-defined threshold ( $\mathrm{COD}_{\text {threshold }}$ ) value of cloud optical depth (COD) at $532 \mathrm{~nm}$. The classification is carried out by considering four values of $\mathrm{COD}_{\text {threshold }}$, for the inter-comparison with INSAT-3D cloud categories. Similarly, comparison of INSAT-3D retrieved CTT is carried out using CALIPSO layer top temperature of topmost cloud layer having high QA values. As mentioned earlier, collocated pixels are identified between INSAT-3D and CALIPSO by using the nearest neighbor approach with a maximum distance of $500 \mathrm{~m}$ separation between centers of the pixels, within $\pm 30 \mathrm{~min}$ temporal difference.

\subsection{Cloud Layer Identification and CTT Retrieval from Radiosonde Profiles}

As part of the validation of satellite retrieved CTT, identification of cloud layers and estimation of CTT is carried out from radiosonde profiles of temperature, pressure and relative humidity (RH). In order to identify cloud layers from radiosonde profiles, RH threshold based cloud detection method proposed by Zhang et al. [68], which is a modified version of Poore et al. [69] and Wang and Rossow [70], 
is used in the present study. The method involves identification of the moisture layer and confirmation of cloud presence in the moisture layer using an altitude depended RH threshold. Extensive description of the methodology is provided in Zhang et al. [68]. It is reported that the cloud layers detected by this scheme is with $53.9 \%$ agreement against ground based active sensors [71]. This method is basically developed for locations within mid-latitude climate regime $\left(32.56^{\circ} \mathrm{N}\right.$ and $\left.116.78^{\circ} \mathrm{E}\right)$. However, Zhang et al. [72] and Narendra Reddy et al. [73] have explored the utility of this method over the tropical climate regime. From the study carried out over tropical western Pacific, Zhang et al. [72] have reported difference of CTH within $500 \mathrm{~m}$ in $66.7 \%$ of clouds detected by this method, in comparison with combined observations of cloud radar, micro-pulse radar and laser ceilometer. In the present study, radiosonde profiles are re-gridded at $50 \mathrm{~m}$ vertical resolution and only those are continuous up to $11 \mathrm{~km}$ altitude are considered for the identification of cloud layers and retrieval of CTT. Maximum and minimum thresholds of RH (RHmax and RHmin) for this purpose are taken as $92 \%$ and $95 \%$ within $0-2 \mathrm{~km}, 90 \%$ and $93 \%$ within $2-6 \mathrm{~km}$ and $88 \%$ and $90 \%$ within $6-11 \mathrm{~km}$. RH is expressed as RH with respect to water (ice) at altitudes where temperature is above (below) $0{ }^{\circ} \mathrm{C}$. A systematic examination of profiles from the surface to the top of the profile is done to detect the presence of moisture layers where RH exceeds the corresponding RHmin. These layers are considered as cloud layers only if the maximum RH within the layer exceeds RHmax corresponding to the base level of that layer. In order to avoid the possibility of misclassifying the moist layer as a cloud, layers with bases within $100 \mathrm{~m}$ from the ground and thickness less than $300 \mathrm{~m}$ are excluded. Finally, the temperature at top of the topmost cloud layer is taken as CTT and is considered for validation of the satellite retrieved CTT.

\section{Results and Discussion}

\subsection{Retrieval of Cloud Mask from INSAT-3D}

The cloud detection algorithm is implemented on INSAT-3D observations and the retrieved cloud mask is shown in Figure 3, for representative days in each season. The region is characterized by a tropical monsoon climate with a distinct seasonality of clouds and precipitation [74]. The figure clearly demonstrates capability of the cloud detection scheme to capture large scale seasonal variations of cloud distribution over the Indian region. Accuracy of the cloud detection is evaluated by inter-comparing the retrieved cloud mask with similar products from active and passive remote sensing sensors. 

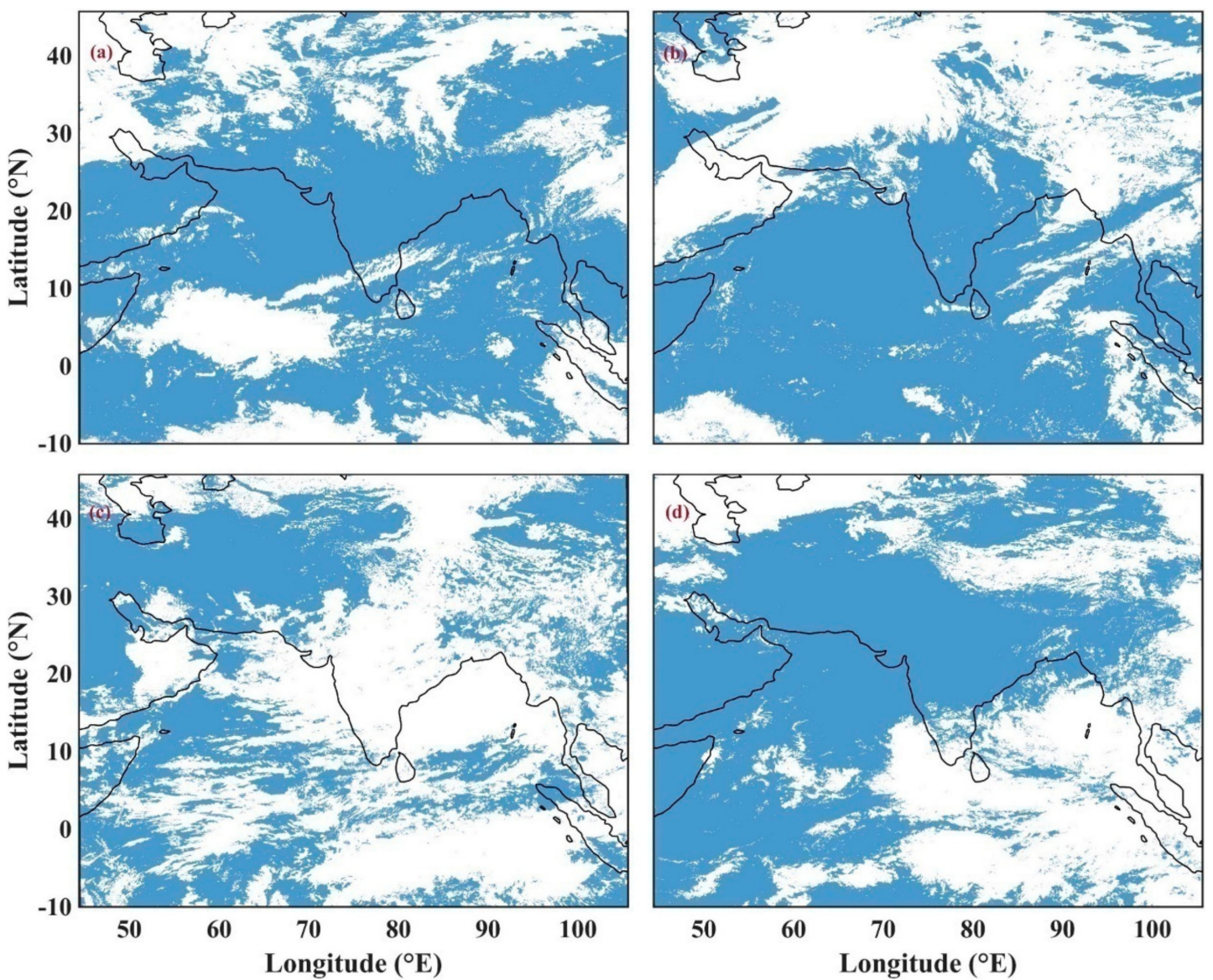

Figure 3. INSAT-3D retrieved cloud mask at 07:30 UTC on (a) Jan 1 (winter season), (b) April 1 (pre-monsoon season), (c) Aug 1 (monsoon season) and (d) Nov 1 (post-monsoon season) of the year 2016. The blue and white colored areas in the figure represent clear-sky and cloudy regions respectively.

\subsection{Comparison of the Cloud Detection Scheme}

Comparison of INSAT-3D retrieved cloud mask using the current algorithm is carried out with collocated measurements from CALIOP and MODIS. Moreover, the developed cloud detection algorithm for INSAT-3D is applied on the radiance from comparable channels of MODIS and compared the output against the CALIOP data. Quantitative outcomes of the above analysis are presented in the form of statistical scores, namely; hit rate, probability of detection (POD) and false alarm rate (FAR). Hit rate is fraction of the correctly detected (in comparison with reference data) cloud and clear pixels out of the total number of pixels considered, whereas POD is fraction of the cloud/clear pixels detected with respect to the reference (CALIOP or MODIS) cloud/clear pixels and FAR is fraction of the falsely identified cloud/clear pixels out of the total number of detected cloud/clear pixels.

\subsubsection{Comparison of INSAT-3D Retrieved Cloud Mask with CALIPSO Cloud Data}

Comparison of the INSAT-3D retrieved cloud mask with the collocated CALIOP cloud product is carried out using data of one year from March, 2016 to February, 2017, which allowed for examining performance of the cloud detection scheme under varying seasonal conditions. Statistical scores generated out of the comparison with CALIOP are tabulated in Table 2. 
Table 2. Inter-comparison of cloud mask algorithm applied to INSAT-3D imager data with clouds from the CALIOP sensor for one year from March, 2016 to February, 2017.

\begin{tabular}{ccccc}
\hline \multirow{2}{*}{ Hit Rate (\%) } & \multicolumn{2}{c}{ Cloudy Regions } & \multicolumn{2}{c}{ Clear Regions } \\
\cline { 2 - 5 } & POD (\%) & FAR (\%) & POD (\%) & FAR (\%) \\
\hline 83.12 & 81.42 & 18.21 & 84.57 & 15.76 \\
\hline
\end{tabular}

INSAT-3D detected cloudy and clear-sky regions agree with the CALIOP retrievals over India and surrounding regions for $83 \%$ of the time. As indicated by the POD values, $81 \%$ of cloud and $85 \%$ of clear-sky pixels in CALIOP products are detected as cloudy and clear-sky respectively by INSAT-3D with the present algorithm. Compared to CALIOP retrievals, $18 \%(16 \%)$ of clear-sky (cloud) pixels are identified falsely as cloudy (clear-sky) by the present algorithm, as indicated by the FAR values. The differences observed are mainly attributed to differences in sensor characteristics and sampling foot prints. CALIOP has a small footprint of $70 \mathrm{~m}$ diameter along its sub-satellite track, where it provides measurements at every $333 \mathrm{~m}$, whereas INSAT-3D data used in the study are at a spatial resolution of $4 \mathrm{~km} \times 4 \mathrm{~km}$. When an INSAT-3D pixel is partially clouded and CALIPSO passed through its cloud free portion, the former detects the pixel as partially cloudy and the latter does as clear, hence leading to an uncertainty in comparison. In order to examine performance of the current algorithm further, these results are compared with the reported comparison results of similar passive sensors with CALIOP retrievals $[39,75,76]$. Comparison statistics of the INSAT-3D cloud mask, along with that from various other sensors around the globe, against the CALIOP cloud mask is summarized in Table 3.

Table 3. Summary of cloud mask comparison results of INSAT-3D and other satellites against CALIOP. Comparison results are presented in terms of probability of detection (POD) of cloudy, POD of clear and hit rate.

\begin{tabular}{|c|c|c|c|c|c|c|c|}
\hline \multirow[b]{2}{*}{ Score } & \multirow{2}{*}{$\begin{array}{c}\text { INSAT-3D } \\
\text { Current } \\
\text { Algorithm }\end{array}$} & \multicolumn{2}{|c|}{ Geostationary Satellite } & \multicolumn{4}{|c|}{ Polar Orbiting } \\
\hline & & $\begin{array}{c}\text { SEVIRI } \\
\text { (Chung et al. } \\
\text { [39]) }\end{array}$ & $\begin{array}{l}\text { SEVIRI (Benas } \\
\text { et al. [75]) }\end{array}$ & $\begin{array}{c}\text { AVHRR-AM } \\
\text { (Stengel et al. } \\
\text { [76]) }\end{array}$ & $\begin{array}{c}\text { AVHRR-PM } \\
\text { (Stengel et al. } \\
\text { [76]) }\end{array}$ & $\begin{array}{c}\text { MODIS- } \\
\text { Terra } \\
\text { (Stengel et al. } \\
\text { [76]) }\end{array}$ & $\begin{array}{c}\text { MODIS- } \\
\text { Aqua } \\
\text { (Stengel et al. } \\
\text { [76]) }\end{array}$ \\
\hline $\begin{array}{l}\text { POD of cloudy } \\
(\%)\end{array}$ & 81.42 & 82.3 & 87.5 & 78.3 & 79.0 & 91.0 & 81.6 \\
\hline $\begin{array}{c}\text { POD of clear } \\
(\%)\end{array}$ & 84.57 & 82.1 & 69.4 & 70.4 & 87.7 & 70.0 & 83.1 \\
\hline Hit rate $(\%)$ & 83.12 & 82.24 & 80.9 & 76.2 & 81.2 & 91.0 & 81.6 \\
\hline Period & $\begin{array}{c}\text { Mar } 2016 \text { to Feb } \\
2017\end{array}$ & $\begin{array}{c}\text { May } 2013 \text { to Apr } \\
2014\end{array}$ & 2006 to 2015 & 2006 to 2014 & 2006 to 2014 & 2006 to 2014 & 2006 to 2014 \\
\hline Region/Coverage & $\begin{array}{c}45.5^{\circ} \mathrm{E}-105.5^{\circ} \mathrm{E} \\
10^{\circ} \mathrm{S}-45.5^{\circ} \mathrm{N}\end{array}$ & $\begin{array}{l}68^{\circ} \mathrm{W}-62^{\circ} \mathrm{E} \\
68^{\circ} \mathrm{S}-68^{\circ} \mathrm{N}\end{array}$ & $\begin{array}{l}60^{\circ} \mathrm{W}-60^{\circ} \mathrm{E} \\
90^{\circ} \mathrm{S}-90^{\circ} \mathrm{N}\end{array}$ & Global & Global & Global & Global \\
\hline Number & 88,383 & 815,961 & 100 million & 42,119 & $16,675,575$ & 19,118 & $16,494,437$ \\
\hline
\end{tabular}

Stengel et al. [76] have evaluated cloud mask from polar orbiting satellite sensors, namely; AVHRR-AM, AVHRR-PM, MODIS-Terra and MODIS-Aqua with collocated measurements of CALIOP. All sensors are observed to be correctly detecting cloud and clear pixels with respect to the active sensor CALIOP, resulting in hit rates ranging from $76 \%$ to $91 \%$ with the highest value for MODIS-Terra and lowest for AVHRR-AM. As indicated by the POD values, 78\%, 79\%, 91\% and $82 \%$ of cloudy conditions are correctly identified by AVHRR-AM, AVHRR-PM, MODIS-Terra and MODIS-Aqua respectively, whereas correctly identified clear-sky is of a slightly lower fraction with POD values of $70 \%, 88 \%, 70 \%$ and $83 \%$ respectively. Likewise, Benas et al. [75] have shown a hit rate of $81 \%$ with POD of cloudy and clear-sky as $88 \%$ and $69 \%$ respectively for SEVIRI, in comparison with CALIOP. At the same time, study by Chung et al. [39] has reported $82 \%$ POD for cloud and clear-sky in comparison between SEVERI and CALIOP. In the same way, Qin et al. [41] quantitatively compared the Himawari satellite retrieved cloud mask over Australian region and found a hit rate of $87 \%$ in reference to CALIOP. Moreover, Jedlovec et al. [55] combined results for night and day of the bi-spectral composite threshold technique 
applied to GOES data in four different seasons, which show a hit rate of $84.5 \%$, with a false alarm rate of $8.1 \%$ and a skill score of $76.4 \%$.

In addition, Stengel et al. [40] applied three state-of-the-art retrieval schemes, namely, CLAVR-x (cloud from AVHRR extended) processing scheme, CM-SAF (climate monitoring satellite application facility) processing scheme and ORAC (Oxford Rutherford Appleton Laboratory retrieval of aerosol and cloud) processing scheme to AVHRR onboard the NOAA-18 and retrieved cloud properties were inter-compared with collocated CALIOP measurements. AVHRR cloud mask evaluation scores in terms of PODs for cloudy scenes were reported to be $82 \%, 82 \%$ and $87 \%$ for CLAVR-x, CM-SAF and ORAC respectively, whereas PODs for clear-sky classification were slightly lower with values $83 \%, 72 \%$ and $61 \%$ respectively for the three schemes. These results show very good agreement of different cloud detection schemes of passive sensors with CALIOP observations and the small biases observed are attributed to differences in sensor characteristics, retrieval approaches and viewing geometrics [40,77]. Space borne passive imagers are reported to be less sensitive to optically thin clouds [40]. Active space borne LIDAR is capable of detecting high altitude thin clouds but may fail in detecting low level clouds due to signal attenuation within thick clouds of COD $>5[36,78,79]$. Though POD of cloud for INSAT-3D is lower than that of SEVIRI and MODIS-Terra, it is better than that of AVHRR-AM and PM. Close agreement among the comparison statistics summarized in Table 3 shows that the cloud mask generated over the Indian region by implementing the present algorithm on INSAT-3D is comparable with the global high quality cloud mask products available from different satellites and hence the INSAT-3D generated cloud mask could be used for generating cloud climatology over the Indian region.

\subsubsection{Comparison of INSAT-3D Retrieved Cloud Mask with MODIS Cloud Data}

In addition to the comparison with CALIOP (active LIDAR sensor) retrievals, cloud mask retrieved by implementing the present algorithm on INSAT-3D is compared with MODIS (passive sensor) cloud mask and the statistical scores are presented in Table 4.

Table 4. Comparison of the cloud mask, generated by implementing the algorithm on INSAT-3D and MODIS, with standard cloud product from MODIS.

\begin{tabular}{ccccccc}
\hline \multirow{2}{*}{ Months } & $\begin{array}{c}\text { Algorithm } \\
\text { Applied to }\end{array}$ & \multirow{2}{*}{ Hit Rate (\%) } & \multicolumn{2}{c}{ Cloudy Regions } & \multicolumn{2}{c}{ Clear Regions } \\
\cline { 5 - 7 } January & INSAT-3D & 79.50 & 66.49 & 6.13 & 94.87 & 29.44 \\
\cline { 2 - 3 } & $\begin{array}{c}\text { MODIS } \\
\text { channels }\end{array}$ & 85.28 & 75.97 & 4.05 & 96.22 & 22.78 \\
\hline \multirow{2}{*}{ June } & $\begin{array}{c}\text { INSAT-3D } \\
\text { MODIS } \\
\text { channels }\end{array}$ & 79.20 & 71.25 & 12.44 & 88.35 & 27.26 \\
\hline
\end{tabular}

The comparison is carried out by using MODIS data during the first fifteen days of the months of January and June in the year of 2016, which are in the winter and monsoon seasons respectively. Comparison with MODIS also shows efficiency of the developed algorithm, with $80 \%$ hit rate in January and $79 \%$ in June. PODs of cloud and clear-sky pixels in January are $66 \%$ and $95 \%$ respectively with FAR $6 \%$ and $29 \%$, whereas POD of cloud and clear pixels in June are $71 \%$ and $88 \%$ with FAR $12 \%$ and $27 \%$. The current algorithm uses only five channels of INSAT-3D for cloud detection, whereas MODIS cloud detection scheme uses up to 22-channels [80]. Thus, the observed differences in cloud detection could mainly be due to the difference in cloud detection techniques employed and channels used in both the satellites, in addition to the differences in spatial resolution and pixel orientation on ground. Moreover, it is also to be noted in contest of this comparison that the MODIS algorithm for cloud mask is clear-sky conservative [47,48], whereas the present algorithm is cloud conservative. 
In general, inter-comparison results yield performance of the algorithm, relative to another, with the differences in several factors including retrieval techniques, sensor specifications, time of observation and spatial resolution. In order to overcome the uncertainties due to these factors, the current algorithm was applied on MODIS allowing for a direct comparison of the resulting cloud mask with the MODIS standard cloud product.

\subsubsection{Implementation of the Algorithm on MODIS}

The present algorithm is implemented on MODIS measurements from the channels similar to those of INSAT-3D and the generated cloud mask is compared with the MODIS standard cloud product. Comparison between the MODIS cloud mask with the current algorithm and standard MODIS cloud product shows a hit rate of $85 \%$ and $83 \%$ in January and June, which is observed to be $80 \%$ and $79 \%$ respectively when the algorithm is implemented on INSAT-3D observations (Table 4). POD of cloud and clear-sky pixels are 76\% (76\%) and 96\% (93\%) in January (June) with FAR 4\% (8\%) and $23 \%(23 \%)$. When compared with the MODIS standard product, the cloud mask generated by implementing the present algorithm on both INSAT-3D and MODIS yielded results in excellent agreement, with a difference in hit rate as low as $6 \%$ and $4 \%$ in January and June respectively. The new cloud mask generated by implementing the current algorithm on MODIS is compared also with the cloud product from CALIOP. A hit rate of $86 \%$ with POD of cloud and clear as $88 \%$ and $83 \%$ respectively are observed in the comparison, as shown in Table 5. Similarly, when Stengel et al. [40] have applied the cloud mask schemes to MODIS channels of comparable wavelengths with those of AVHRR, agreement reported was with POD of cloud (clear-sky) $84 \%$ (85\%), 86\% (69\%) and 90\% (62\%) for CLAVR-x, CM SAF and ORAC respectively. Thus the comparison results and their closeness with those of other passive satellites ensure consistency and efficiency of the cloud detection scheme employed in the present algorithm in retrieving the cloud mask using INSAT-3D.

Table 5. Evaluation scores of MODIS cloud masks with different algorithms, using CALIPSO as a reference. Evaluation scores are represented with probability of detection (POD), hit rate and Heidke skill score (HSS).

\begin{tabular}{ccccc}
\hline \multirow{2}{*}{ Score } & \multicolumn{4}{c}{ MODIS } \\
\cline { 2 - 5 } & $\begin{array}{c}\text { Current } \\
\text { Algorithm }\end{array}$ & $\begin{array}{c}\text { CLAVR-x } \\
\text { (Stengel et al. [40]) }\end{array}$ & $\begin{array}{c}\text { CM SAF } \\
\text { (Stengel et al. [40]) }\end{array}$ & $\begin{array}{c}\text { ORAC } \\
\text { (Stengel et al. [40]) }\end{array}$ \\
\hline POD of cloud (\%) & 87.67 & 84 & 86 & 90 \\
POD of clear-sky & 83.24 & 85 & 69 & 62 \\
$(\%)$ & 0.69 & 0.66 & 0.55 & 0.54 \\
HSS & 85.99 & - & - & - \\
Hit rate (\%) & & &
\end{tabular}

\subsection{Cloud Classification from INSAT-3D and Inter-Comparison with CALIPSO}

Retrieval of CTT is carried out, after categorizing the detected cloud pixels of INSAT-3D into different cloud types (high level opaque, low level opaque, STC and partial clouds as detailed in the methodology Section 3.2). Comparison of these four categories of clouds is carried out with collocated CALIPSO cloud pixels for a period of one year from March, 2006 to February, 2017, though a one to one relation is not expected between cloud classes from INSAT-3D and CALIPSO due to the differences in defining cloud categories. As detailed in Section 3.5, single layer cloud pixels from CALIOP are categorized into thick and thin clouds, based on pre-defined threshold values of $C O D\left(\mathrm{COD}_{\text {threshold }}\right)$. Pixels with $C O D \geq C O D_{\text {threshold }}$ are defined as thick and those with $C O D<\mathrm{COD}_{\text {threshold }}$ are considered as thin clouds. Hamann et al. [3] have used a threshold of 3 for classifying CALIOP identified clouds as thick and thin for comparing with clouds from the passive sensor SEVIRI. As per ISCCP classification, clouds with COD less than 3.6 are considered as thin clouds. In the present study, an analysis is carried out by considering four different values $\left(1,2,3\right.$ and 3.6) of $C O D_{\text {threshold }}$ for classifying clouds from 
CALIOP into thick and thin classes. Table 6 shows the percentage of detected pixels of each category from INSAT-3D that falls into the thin and thick classes from CALIPSO.

Table 6. Inter-comparison of INSAT-3D cloud categories with clouds from CALIPSO. Values represent the percentage of pixels of each cloud class of INSAT-3D that falls into each CALIPSO class.

\begin{tabular}{cccccccccc}
\hline \multirow{2}{*}{ Cloud Categories } & \multicolumn{8}{c}{ CALIPSO } \\
\cline { 3 - 10 } & \multicolumn{2}{c}{$\mathbf{C O D}_{\text {threshold }}=\mathbf{1}$} & $\mathbf{C O D}_{\text {threshold }}=\mathbf{2}$ & $\mathbf{C O D}_{\text {threshold }}=\mathbf{3}$ & $\mathbf{C O D}_{\text {threshold }}=\mathbf{3 . 6}$ \\
\cline { 3 - 10 } & Thick & Thin & Thick & Thin & Thick & Thin & Thick & Thin \\
\hline \multirow{3}{*}{ INSAT-3D } & High level opaque & 95 & 5 & 92 & 8 & 81 & 19 & 69 & 31 \\
& Low level opaque & 90 & 10 & 86 & 14 & 83 & 17 & 81 & 19 \\
& STC clouds & 53 & 47 & 44 & 56 & 38 & 62 & 31 & 69 \\
& Partial clouds & 87 & 13 & 83 & 17 & 71 & 29 & 59 & 41 \\
\hline
\end{tabular}

It is observed from Table 6 that the majority of high level and low level opaque clouds from INSAT-3D fall under the CALIOP class of optically thick clouds in visible wavelength. As seen in the table, $81 \%$ to $90 \%$ of low level opaque clouds from INSAT-3D are identified as optically thick clouds by CALIPSO, with COD threshold values ranging from 3.6 to 1 . In case of high level opaque clouds, 95\% are observed to be with COD greater than 1 and $69 \%$ are with COD greater than 3.6. Out of the STC cloud pixels, $69 \%$ are observed to be in the thin cloud category of CALIPSO, with a $\mathrm{COD}_{\text {threshold }}$ of 3.6. However, $59 \%$ of partial clouds from INSAT-3D are observed to be optically thick with visible optical depth greater than 3.6. This could be partly due to the small foot print of CALIPSO, compared to the INSAT-3D pixel resolution. Clouds that are partially filled within a $4 \mathrm{~km} \times 4 \mathrm{~km}$ pixel of INSAT-3D may lead to complete coverage of several CALIOP foot prints, which are of only $70 \mathrm{~m}$ diameter, within the INSAT-3D pixel. High fraction of opaque clouds and STC clouds falling under optically thick and thin clouds respectively show a fair agreement of INSAT-3D cloud classes to CALIPSO categories for single layer clouds. Differences are expected between the cloud classes of INSAT-3D and those of CALIOP, due to differences in criteria used for the classification, in addition to the differences in spatial resolution, time of observation and retrieval techniques. Disagreements between cloud classes from passive and active sensors, due to difference in cloud class definitions, are reported in earlier studies [81]. Considering the ability of CALIPSO to detect very thin clouds $[36,38]$, the fraction of STC clouds detected by INSAT-3D to total thin cirrus detected by CALIPSO is examined and the results are tabulated in Table 7. In order to classify thin and thick cirrus clouds from CALIPSO, Sassen et al. [38] have used a COD of 0.3 as the threshold. Here, the analysis is carried out for three values of $\mathrm{COD}_{\text {threshold }} ; 0.3,0.5$ and 1.0. Pixels with $\mathrm{COD}<\mathrm{COD}_{\text {threshold }}$ and $\mathrm{CTH}>8 \mathrm{~km}$ are classified as thin cirrus clouds from CALIPSO.

Table 7. Inter-comparison of INSAT-3D semi-transparent cirrus (STC) clouds and thin cirrus class from CALIPSO. Values represent the percentage of pixels of STC clouds of INSAT-3D to the total thin cirrus clouds of CALIPSO.

\begin{tabular}{cccc}
\hline \multirow{2}{*}{ Cloud Category } & \multicolumn{3}{c}{ CALIPSO } \\
\cline { 2 - 4 } & $\mathrm{COD}_{\text {threshold }}=\mathbf{0 . 3}$ & $\mathrm{COD}_{\text {threshold }} \mathbf{= 0 . 5}$ & COD $_{\text {threshold }}=\mathbf{1}$ \\
\hline STC Clouds & 84 & 85 & 86 \\
\hline
\end{tabular}

It can be seen from Table 7 that $84 \%$ of the thin cirrus clouds with a COD $<0.3$ from CALIPSO are detected as STC clouds by INSAT-3D. However, the fraction increases to $86 \%$ when the $\mathrm{COD}_{\text {threshold }}$ increases to 1 . This shows the capability of the present algorithm implemented on INSAT-3D to detect even optically thin clouds with excellent accuracy. 


\subsection{Retrieval of CTT}

Retrieval of CTT is carried out by applying suitable methods for each of the four cloud categories of INSAT-3D (as detailed in the methodology Sections 3.2 and 3.2.1). Figure 4 shows retrieved CTT, by applying the present algorithm on INSAT-3D retrieved cloud mask for the same representative days in each season as shown in Figure 3. CTT values over India and the surrounding regions varied from 180 to $290 \mathrm{~K}$, with deep convective cloud structures (i.e., CTT < $250 \mathrm{~K}$ ) during the monsoon and post-monsoon seasons. The spatial variations of CTT observed indicate the general consensus of less organized cloud systems over the Indian region during winter and pre-monsoon season, compared to that in monsoon season. Clouds retreated towards the equator from the subcontinent in the post-monsoon season, after its wide spreading in the monsoon season, which is seen in the figure.
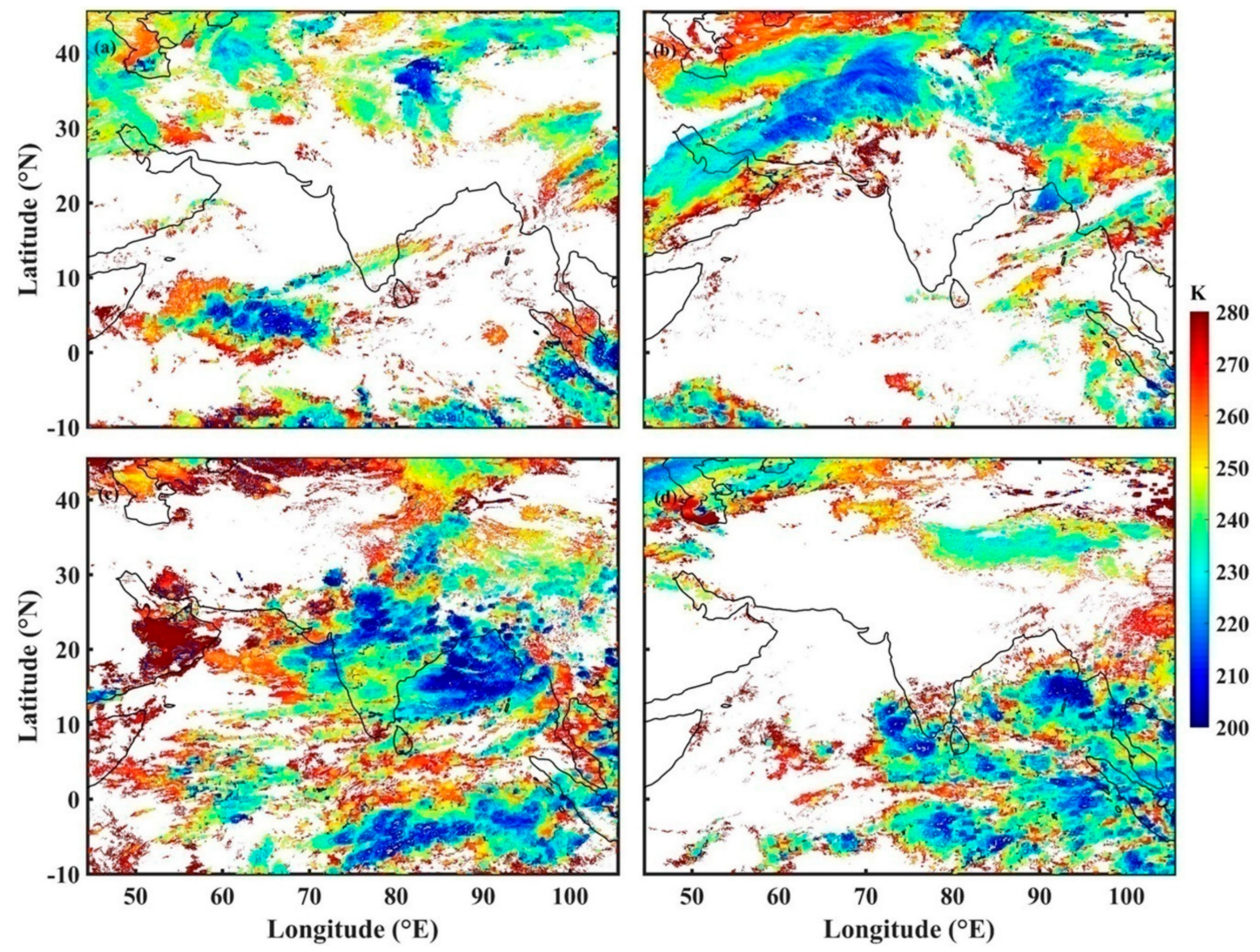

Figure 4. INSAT-3D retrieved cloud top temperature (CTT) at 07:30 UTC on (a) January 1 (winter season), (b) April 1 (pre-monsoon), (c) August 1 (monsoon) and (d) Novmber 1 (post-monsoon) of the year 2016 .

\subsection{Validation of INSAT-3D Retrieved CTT}

Validation of INSAT-3D retrieved CTT is carried out, using concurrent radiosonde measurements. Outcomes of the comparison analysis are presented in terms of mean bias error, mean absolute error and root mean square error (RMSE). Figure 5 depicts scatter plot between CTTs from INSAT-3D and collocated radiosonde measurements. Radiosonde measurements above $11 \mathrm{~km}$ altitude (below $\sim 200$ $\mathrm{hPa}$ ) are not considered in the analysis to avoid the possibility of errors due to relative humidity uncertainties. This restriction has reduced number of data points available for comparison and limited the minimum CTT value to about $235 \mathrm{~K}$. CTT from INSAT-3D and radiosonde agrees well within $7.90 \mathrm{~K}$, with a RMSE of $10.30 \mathrm{~K}$ and mean bias error of $-0.31 \mathrm{~K}$. The observed difference in CTT could be partially due to temporal differences between the satellite observations and radiosonde 
measurements, and inherent biases of the methods. However, such differences are similar to those previously published [82,83]. For instance, Zhang et al. [72] have compared the radiosonde based cloud layer retrieval with a ground-based active remote sensing of cloud (ARSCL) value-added product, which combines data from 95-GHz W-band atmospheric radiation measurement (ARM) cloud radar and/or the $35-\mathrm{GHz}$ millimeter microwave cloud radar, over multiple atmospheric radiation measurement sites. Absolute differences in CTHs from radiosonde and ARSCL retrievals were reported to be less than $500 \mathrm{~m}$ for $78.7 \%, 66.7 \%$ and $61.2 \%$ of the cases analyzed over the Southern Great Plains, tropical western Pacific and North Slope of Alaska sites respectively. In view of these results, it could be concluded that the observed differences in CTT between INSAT-3D and radiosonde, which are within $3 \%$, could be due to the inherent limitations of sensors and methodologies. However, to gain a better understanding of these discrepancies over a wide range of temperatures, a detailed comparison is carried out with collocated CALIOP measurements over a large spatial domain.

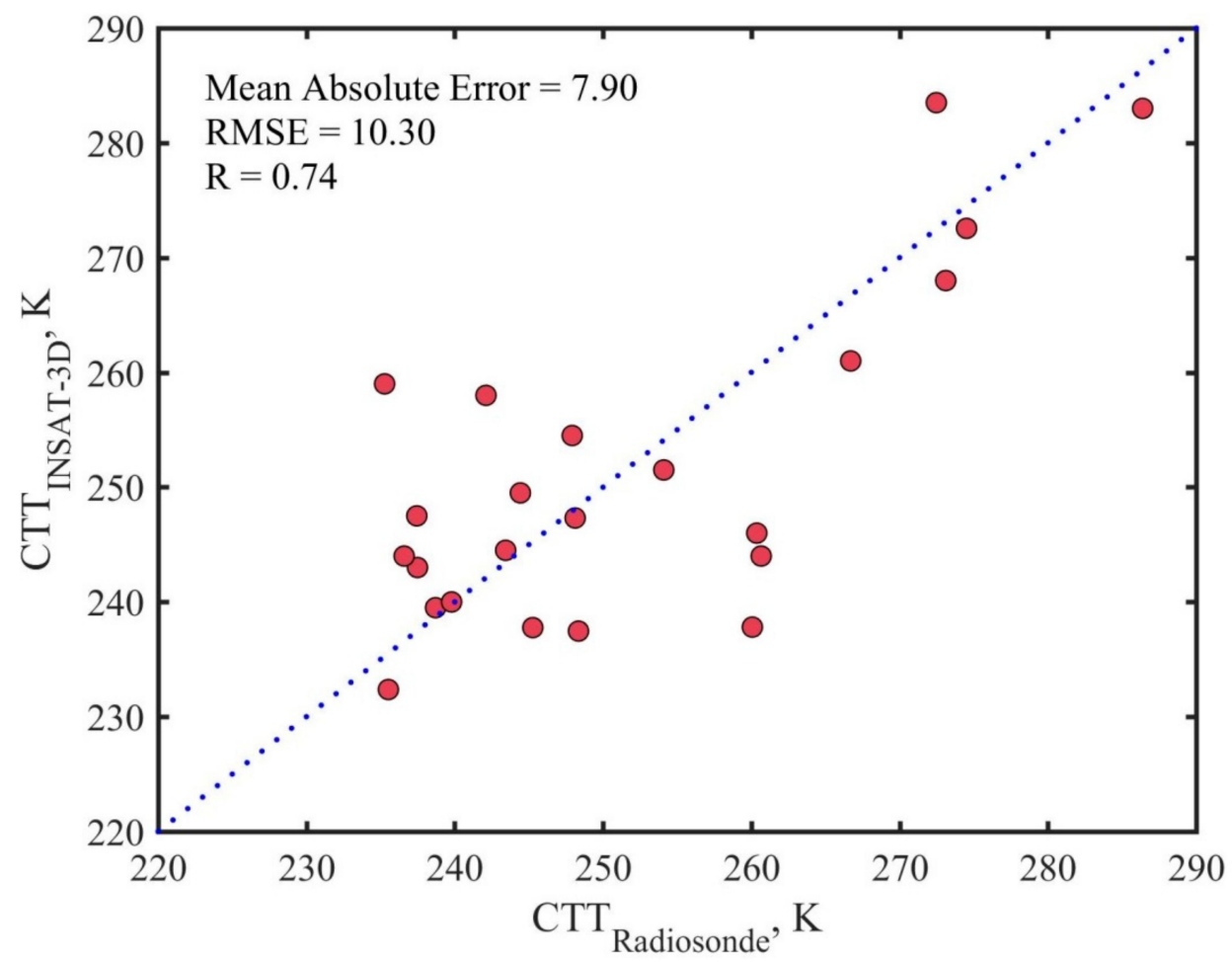

Figure 5. Comparison of retrieved CTT (Kelvin) from INSAT-3D, with that from radiosonde profiles.

\subsection{Comparison of INSAT-3D Retrieved CTT using CALIPSO}

In addition to the validation with radiosonde estimates, INSAT-3D retrieved CTT is compared with CTT from CALIOP. Conversion of CTH measured by CALIOP to CTT uses temperature profiles from MERRA-2 as mentioned in the data section. MERRA-2 gives temperature profiles at 72 vertical levels up to $0.01 \mathrm{hPa}$ with a horizontal resolution of $0.625^{\circ}$ longitude $\times 0.5^{\circ}$ latitude [84]. $\mathrm{CTH}$ measurements from CALIOP have a spatial resolution of $5 \mathrm{~km}$ and vertical resolution of $30 \mathrm{~m}$ up to altitude of $8.2 \mathrm{~km}$ and $60 \mathrm{~m}$ above $8.2 \mathrm{~km}$. This difference in the horizontal and vertical resolution between MERRA-2 and CALIOP causes uncertainties in the estimated CTT of CALIOP from CTH. However, several studies have reported the inter-comparison of CTT from CALIOP and that of passive satellite sensors $[75,85,86]$. Since geostationary satellites are performing measurements over different regions of the globe, direct comparison of retrievals from these satellites are not possible. Relative assessment of retrievals from these geostationary satellites is possible by the comparisons using common datasets, such as CALIPSO CTT. Thus, the comparison of CTTs from INSAT-3D and CALIPSO would be useful for future global studies, which require combination of cloud retrievals from different geostationary satellites. The comparison is carried out by considering all concurrent and collocated pixels of INSAT-3D, except 
those are flagged with low confidence. Limitations in the comparison of CTT from satellite sensors with CALIPSO CTT is discussed in detail in the literature [86,87]. Major disagreement is reported for thin cloud layers, which is mainly attributed to lower sensitivity of passive sensors to high level thin clouds with low optical depth. Benas et al. [75] have reported significant improvement in agreement between CTT from SEVERI and CALIOP, when optically thin clouds are not included for the comparison. The presence of multi-layer clouds is also reported to be affecting the agreement between cloud top properties from active and passive satellites. Based on the comparison between CTH from SEVIRI and CALIOP with single and multi-layer clouds, Hamann et al. [3] have reported an increase in bias of more than $2 \mathrm{~km}$ in presence of multi-layer clouds. In view of this, inter-comparison of CTT from INSAT-3D and CALIOP has been performed, for single and multi-layer clouds, by including and excluding optically thin clouds with optical depths ranging from 0.25 to 1 . The results are summarized in Table 8, in which values inside bracket represent the comparison statistics of single layer (SL) clouds, whereas those outside represent that of single and multi-layer (ML) clouds together.

Table 8. Inter-comparison of INSAT-3D retrieved CTT against CALIPSO for single and multi-layer clouds with varying cloud optical depth (COD) values of top layer.

\begin{tabular}{ccccc}
\hline $\begin{array}{c}\text { Thresholds of } \\
\text { COD }\end{array}$ & $\begin{array}{c}\text { Mean Bias Error } \\
\text { ML (SL) }\end{array}$ & $\begin{array}{c}\text { Mean Absolute } \\
\text { Error } \\
\text { ML (SL) }\end{array}$ & $\begin{array}{c}\text { RMSE } \\
\text { ML (SL) }\end{array}$ & $\begin{array}{c}\text { Correlation } \\
\text { Coefficient } \\
\text { ML (SL) }\end{array}$ \\
\hline No threshold & $12.63(9.07)$ & $16.27(13.56)$ & $22.90(19.40)$ & $0.62(0.73)$ \\
COD $>0.25$ & $10.41(8.07)$ & $13.93(12.19)$ & $19.30(16.91)$ & $0.73(0.80)$ \\
COD $>0.50$ & $8.68(6.87)$ & $12.38(11.12)$ & $16.65(14.99)$ & $0.81(0.85)$ \\
COD $>0.75$ & $8.07(6.65)$ & $11.80(10.81)$ & $15.95(14.51)$ & $0.83(0.87)$ \\
COD $>1.00$ & $7.45(6.31)$ & $11.23(10.61)$ & $15.20(14.32)$ & $0.85(0.87)$ \\
\hline
\end{tabular}

COD: cloud optical depth; ML: single and multi-layer clouds, SL: single layer cloud only.

It can be noticed from the table that the agreement is better for single layer clouds, compared to that for multilayer clouds, in all the cases considered. Even when all the optically thin clouds are included in comparison, CTTs from INSAT-3D and CALIOP agree within the mean bias error of $12.63 \mathrm{~K}$ (9.07), mean absolute error of $16.27 \mathrm{~K}$ (13.56), RMSE of $22.90 \mathrm{~K}$ (19.40) and coefficient of correlation of 0.62 (0.73) for ML (SL) clouds. However, the agreement is observed to be improving when optically thin clouds are excluded from the analysis. When only single layer clouds with COD $>1$ are considered for the analysis, mean bias error, mean absolute error, RMSE and coefficient of correlation are observed to be $6.31 \mathrm{~K}, 10.61 \mathrm{~K}, 14.32 \mathrm{~K}$ and 0.87 respectively, as shown in Figure 6. These results presented are subjected to the uncertainties associated with CALIPSO CTT. However, it can be noted here that the effect of multilayer clouds decreases with an increase in optical depth of the top layer cloud. The improvements in the comparison observed here with an increase in COD in the absence of multi-layer clouds only indicate removal of bias due to sensitivity difference between the datasets rather than bias in the retrieval procedure. It can be noted that the reduction in biases observed in the absence of optically thin clouds is not high, which indicates capability of the present algorithm to efficiently retrieve CTT even over optically thin clouds.

By evaluating SEVIRI retrieved CTT dataset against CALIOP data, Taylor et al. [86] have reported large spatio-temporal variability in absolute retrieval biases, varying from less than $5 \mathrm{~K}$ to $30 \mathrm{~K}$. Hamann et al. [3] also have reported $40 \%(20 \%)$ deviations in CTH retrieval from SEVERI over tropics (extra-tropics), leading to $1.0-2.5 \mathrm{~km}$ difference in CTH, in comparison with CALIOP measurements. Overall, biases of INSAT-3D retrieved CTT in the present study are comparable to the reported discrepancy of $0.5-3.0 \mathrm{~km}$, which is approximately $3-20 \mathrm{~K}$ by assuming a lapse rate of $6.5 \mathrm{Kkm}^{-1}[83,87-89]$. 


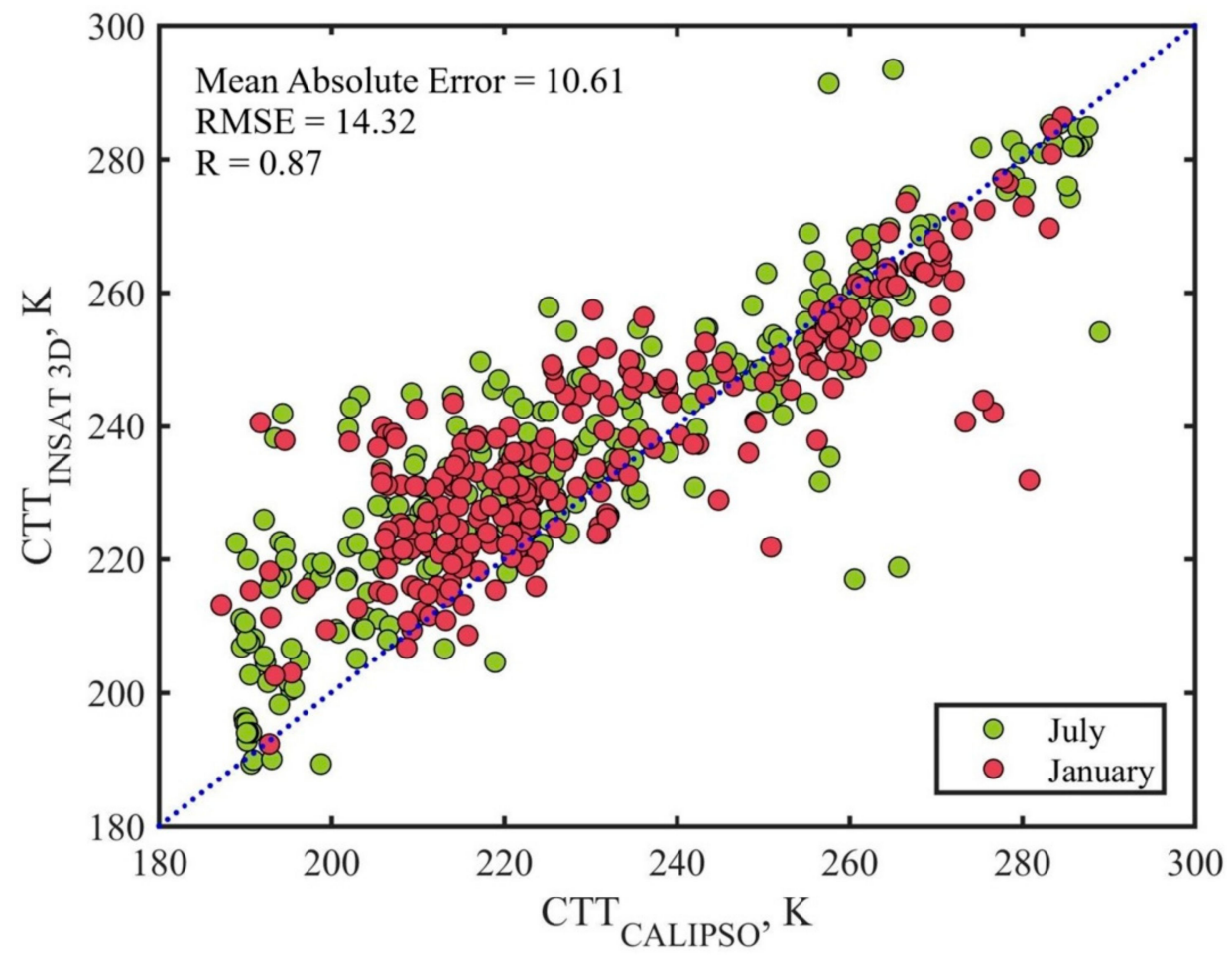

Figure 6. Comparison of retrieved CTT (Kelvin) from INSAT-3D, with that from CALIPSO, by considering only the pixels with full confidence (opaque and STC/partial in conditions (i) and (iv)) from INSAT-3D. Five hundred and seventeen data points are included in the analysis.

\subsection{Sensitivity of CTT Retrieval to Cloud Classification Scheme}

Since different methods are employed for CTT retrieval of different types of clouds, based on their opacity, cloud classification is critical and crucial in CTT retrieval. For optically thick clouds, emissivity is assumed to be unity and hence the measured $\mathrm{BT}_{\mathrm{TIR} 1}$ is taken as CTT. This makes the threshold used for segregating optically thick clouds so important in CTT retrieval. Hence a sensitivity analysis is carried out, for SL and ML clouds; by considering different thresholds for high level and low level optically thick clouds and the results are summarized in Table 9. Several earlier studies (Hamada et al. [90], Inoue [61,62] and Lutz et al. [91]) have considered BTD segregating high (low) level thick clouds. With these thresholds, mean bias error, mean absolute error, RMSE and correlation coefficient in comparison between CTT from INSAT-3D and CALIOP are observed to be $11.60 \mathrm{~K}$ (10.45), $14.23 \mathrm{~K}$ (13.40), $18.52 \mathrm{~K}$ (17.45) and 0.81 (0.84) for ML (SL) clouds. The agreement between CTT from both the satellites is observed to be improving when BTD TIR1,TIR2 $_{1}$ thresholds for high level thick clouds are made more stringent from $2.5 \mathrm{~K}$ to $0.5 \mathrm{~K}$. In this case, mean bias error, mean absolute error, RMSE and correlation coefficient are observed to be $7.45 \mathrm{~K}(6.31)$, $11.23 \mathrm{~K}(10.61), 15.20 \mathrm{~K}(14.32)$ and 0.85 (0.87) respectively, for ML (SL) clouds. Decrease in mean bias error of $4.15 \mathrm{~K}(4.14 \mathrm{~K})$ and increase in correlation coefficient from 0.81 to 0.85 (0.84 to 0.87$)$ was

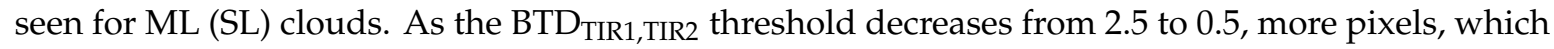
are earlier classified as opaque clouds, fall into the category of partial clouds and hence the CTT retrieval for partial clouds detailed in Section 3.2.1 is employed instead of just considering BT $\mathrm{T}_{\mathrm{TIR} 1}$ as

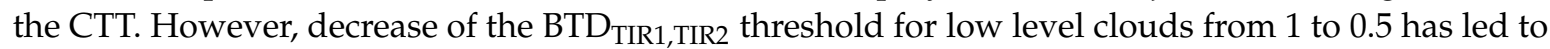
deterioration of the statistical scores. Based on this sensitivity analysis, BTD $_{\text {TIR1,TIR2 }}$ of $0.5 \mathrm{~K}(1 \mathrm{~K})$ was used in the present algorithm to segregate high (low) level thick clouds for further retrieval of CTT. 
Table 9. Inter-comparison of INSAT-3D retrieved CTT against CALIPSO for different thresholds of cloud classification.

\begin{tabular}{|c|c|c|c|c|}
\hline Conditions & $\begin{array}{l}\text { Mean Bias Error } \\
\text { ML (SL) }\end{array}$ & $\begin{array}{c}\text { Mean Absolute Error } \\
\text { ML (SL) }\end{array}$ & $\begin{array}{l}\text { RMSE } \\
\text { ML (SL) }\end{array}$ & $\begin{array}{c}\text { Correlation Coefficient } \\
\text { ML (SL) }\end{array}$ \\
\hline $\begin{array}{l}\text { High level thick clouds: } \\
\mathrm{BT}_{\text {TIR1 } 1<250 \text { and } 0 \leq}< \\
\text { BTD }_{\text {TIR1,TIR2 }} \leq 2.5 \\
\text { Low level thick clouds: } \\
\mathrm{BT}_{\text {TIR1 } 1 \geq 250 \text { and } 0 \leq} \\
\text { BTD }_{\text {TIR1,TIR2 } 2} \leq 1.0\end{array}$ & $11.60(10.45)$ & $14.23(13.40)$ & $18.52(17.45)$ & $0.81(0.84)$ \\
\hline $\begin{array}{l}\text { High level thick clouds: } \\
\text { BT }_{\text {TIR1 } 1<250 \text { and } 0 \leq} \\
\text { BTD }_{\text {TIR1,TIR2 } 2} \leq 1.0 \\
\text { Low level thick clouds: } \\
\text { BT }_{\text {TIR } 1 \geq 250 \text { and } 0 \leq} \leq \\
\text { BTD }_{\text {TIR1,TIR } 2} \leq 1.0\end{array}$ & $9.39(8.23)$ & $12.33(11.47)$ & $16.51(15.36)$ & $0.84(0.87)$ \\
\hline $\begin{array}{l}\text { High level thick clouds: } \\
\mathrm{BT}_{\text {TIR1 } 1}<250 \text { and } 0 \leq \\
\text { BTD }_{\text {TIR1,TIR2 }} \leq 0.5 \\
\text { Low level thick clouds: } \\
\text { BT }_{\text {TIR1 } 1 \geq 250 \text { and } 0 \leq} \\
\text { BTD }_{\text {TIR1,TIR2 }} \leq 1.0 \\
\end{array}$ & $7.45(6.31)$ & $11.23(10.61)$ & $15.20(14.32)$ & $0.85(0.87)$ \\
\hline $\begin{array}{l}\text { High level thick clouds: } \\
\text { BT }_{\text {TIR1 } 1<250 \text { and } 0 \leq} \\
\text { BTD }_{\text {TIR1,TIR2 } 2} \leq 0.5 \\
\text { Low level thick clouds: } \\
\text { BT }_{\text {TIR } 1 \geq 250 \text { and } 0 \leq} \leq \\
\text { BTD }_{\text {TIR1,TIR2 }} \leq 0.5\end{array}$ & $8.37(7.24)$ & 11.69 (11.01) & 15.78 (14.79) & $0.83(0.86)$ \\
\hline
\end{tabular}

\subsection{Sensitivity of CTT to the Retrieval Criteria}

While CTT of optically thick cloud is considered as the BT $\mathrm{TIR}_{1}$, that of the STC and partial cloud is retrieved through the best fit on a two dimensional scatter plot between $\mathrm{BT}_{\mathrm{TIR} 1}$ and $\mathrm{BTD}_{\mathrm{TIR} 1, \mathrm{TIR} 2}$ over a region consisting of clear, opaque, STC/partial clouds. In order to get the best retrieval, the region considered around the pixel must contain sufficient number of opaque, STC/ partial clouds and clear pixels. However, it is observed that several of the pixels did not meet these criteria and it led to elimination of them from the retrieval. In order to avoid exclusion of these pixels, an analysis is carried out to understand the sensitivity of these stringent conditions and also to explore the possibility to relax these criteria without compromising quality of the product. In this regard, six sets of conditions are followed for retrieval of CTT of STC and partial clouds and the retrieved CTT in each case is compared with the CTT from CALIOP. Among the six sets of conditions, which are given below, the first three are for STC and the remaining three are for partial clouds.

Conditions for the STC clouds are that the area considered must contain:

(i) At least one high level opaque cloud, STC cloud and clear sky pixel.

(ii) At least one pixel of high level opaque cloud.

(iii) At least 25 cloud pixels irrespective of any of the conditions.

Conditions for partial clouds are that the area considered must contain:

(iv) At least one opaque cloud (high/low), partial and clear sky pixel.

(v) At least one pixel of opaque cloud (high/low).

(vi) At least 25 cloud pixels, irrespective of any of the conditions.

Table 10 shows the results of comparison of INSAT-3D retrieved CTT, by following the above set of conditions, with CALIOP CTT. Though only those pixels, which satisfy conditions (i) and (iv) are considered as confident in the CTT retrieval scheme, the comparison statistics indicate that the pixels those satisfy conditions (ii), (v) and (vi) are also quite acceptable. It could be noted that the conditions (iii) and (vi) are the same, but the former is for STC and the latter is for partial clouds, which 
demands only 25 pixels, irrespective of any other conditions. Conditions (iii) and (vi) provided better CTT retrieval for partial clouds than STC. The sensitivity analysis reveals that five out of six conditions, though four of them are not considered with full confidence, provide CTT retrieval with good accuracy.

Table 10. Inter-comparison of INSAT-3D retrieved CTT against CALIPSO with different conditions (given in Section 4.8) for retrieval over STC and partial clouds.

\begin{tabular}{ccccc}
\hline $\begin{array}{c}\text { Condition } \\
\text { Numbers }\end{array}$ & Mean Bias Error & $\begin{array}{c}\text { Mean Absolute } \\
\text { Error }\end{array}$ & RMSE & $\begin{array}{c}\text { Correlation } \\
\text { Coefficient }\end{array}$ \\
\hline (i) & 8.14 & 11.59 & 15.27 & 0.84 \\
(ii) & 9.64 & 12.43 & 16.56 & 0.82 \\
(iii) & 7.11 & 13.51 & 19.78 & 0.76 \\
(iv) & 6.15 & 9.59 & 12.94 & 0.91 \\
(v) & 6.94 & 10.13 & 13.71 & 0.88 \\
(vi) & 8.73 & 10.69 & 14.03 & 0.90 \\
\hline
\end{tabular}

\section{Conclusions}

Accurate retrieval of cloud parameters such as cloud mask and CTT at sufficient spatial and temporal resolutions is essential for climate studies. Diurnal variations of cloud parameters over a large spatial domain can only be achieved using observations from geostationary satellite sensors. Imager on INSAT-3D is one among them, which provides observations over the Indian region at an interval of half an hour. An algorithm is developed in the present study to retrieve the cloud mask and cloud top temperature using INSAT-3D observations. Reliability of the parameters retrieved by implementing the developed algorithm on INSAT-3D is examined through inter-comparisons with the cloud mask and cloud top temperature (CTT) from MODIS and CALIOP and also through validation with conventional radiosonde measurements. In addition, the cloud mask scheme is implemented on similar channels of MODIS and the retrievals are inter-compared. The current algorithm implemented on INSAT-3D is observed to be capable of generating cloud mask with $\sim 85 \%$ accuracy, as evidenced by the comparison analysis. Further, validation results indicate that the uncertainty associated with CTT retrieval using INSAT-3D is 3\%. Reliability and consistency of the retrieved products are further ensured by comparing the current comparison statistics with that of the same products from other satellites over different regions of the globe. Excellent comparison scores and their close agreement with reported similar comparisons show the efficiency of the present algorithm to apply for operational generation of these essential climate variables to create long-term climate quality data over the Indian region.

Supplementary Materials: The following are available online at http://www.mdpi.com/2072-4292/11/23/2811/s1.

Author Contributions: Conceptualization, M.V.R.; methodology, C.B.L., S.S.P. and M.V.R.; software, C.B.L. and S.S.P.; validation, C.B.L., S.S.P. and M.V.R.; formal analysis, C.B.L.; investigation, C.B.L. and S.S.P.; data curation, C.B.L. and S.S.P.; Writing-original draft preparation, M.V.R., C.B.L. and S.S.P.; Writing-review and editing, M.V.R., C.B.L., S.S.P., M.V.R.S.S., P.V.N.R. and K.N.; visualization, C.B.L. and S.S.P.; supervision, M.V.R., M.V.R.S.S., P.V.N.R., and K.N.; project administration, M.V.R.S.S. and M.V.R.; funding acquisition, M.V.R.S.S.

Funding: This research and the APC are funded by National Information System for Climate and Environment Studies (NICES) program of ISRO.

Acknowledgments: One of the co-authors, C.B. Lima, gratefully acknowledges the fellowship support received from National Information System for Climate and Environment Studies (NICES) program of ISRO. This work was carried out within the framework of the climate monitoring of NICES program. We thank Director, NRSC for all the supports provided to carry out this work. INSAT-3D imager data are provided by the ISRO through MOSDAC portal of SAC. Very special thanks are offered to SDSC-SHAR for providing the radiosonde dataset. We would like to thank the MODIS and CALIPSO science team for providing accessibility to data products that made this study possible. CALIPSO data set is obtained from NASA Langley Research Center Atmospheric Science Data Center (http://eosweb.larc.nasa.gov/), MODIS cloud data from NASA LAADS Web (http://ladsweb.nascom.nasa.gov/) and MODIS SST data through https://oceancolor.gsfc.nasa.gov/. Global digital elevation data (GTOPO30) used in the study is obtained through Tropospheric Emission Monitoring Internet Service (TEMIS). Also, we thank the editors and three anonymous reviewers for the suggestions that have improved the manuscript.

Conflicts of Interest: The authors declare no conflict of interest. 


\section{References}

1. Bojinski, S.; Verstraete, M.; Peterson, T.C.; Richter, C.; Simmons, A.; Zemp, M. The Concept of Essential Climate Variables in Support of Climate Research, Applications, and Policy. Bull. Am. Meteorol. Soc. 2014, 95, 1431-1443. [CrossRef]

2. Hollmann, R.; Merchant, C.J.; Saunders, R.; Downy, C.; Buchwitz, M.; Cazenave, A.; Chuvieco, E.; Defourny, P.; de Leeuw, G.; Forsberg, R.; et al. The ESA Climate Change Initiative: Satellite Data Records for Essential Climate Variables. Bull. Am. Meteorol. Soc. 2013, 94, 1541-1552. [CrossRef]

3. Hamann, U.; Walther, A.; Baum, B.; Bennartz, R.; Bugliaro, L.; Derrien, M.; Francis, P.N.; Heidinger, A.; Joro, S.; Kniffka, A.; et al. Remote sensing of cloud top pressure/height from SEVIRI: Analysis of ten current retrieval algorithms. Atmos. Meas. Tech. 2014, 7, 2839-2867. [CrossRef]

4. Berry, E.; Mace, G.G. Cloud properties and radiative effects of the Asian summer monsoon derived from A-Train data. J. Geophys. Res. 2014, 119, 9492-9508. [CrossRef]

5. Hartmann, D.L.; Doelling, D. On the net radiative effectiveness of clouds. J. Geophys. Res. 1991, 96, 869-891. [CrossRef]

6. Liou, K.-N.; Liou, K.-N. Influence of Cirrus Clouds on Weather and Climate Processes: A Global Perspective. Mon. Weather Rev. 1986, 114, 1167-1199. [CrossRef]

7. Lolli, S.; Campbell, J.R.; Lewis, J.R.; Gu, Y.; Marquis, J.W.; Chew, B.N.; Liew, S.C.; Salinas, S.V.; Welton, E.J. Daytime top-of-the-atmosphere cirrus cloud radiative forcing properties at Singapore. J. Appl. Meteorol. Climatol. 2017, 56, 1249-1257. [CrossRef]

8. Ramanathan, V.; Inamdar, A. The radiative forcing due to clouds and water vapor. Front. Clim. Model. 2006, 119-151.

9. Schumann, U.; Mayer, B.; Graf, K.; Mannstein, H. A parametric radiative forcing model for contrail cirrus. J. Appl. Meteorol. Climatol. 2012, 51, 1391-1406. [CrossRef]

10. Kiehl, J.T. On the observed near cancellation between longwave and shortwave cloud forcing in tropical regions. J. Clim. 1994, 7, 559-565. [CrossRef]

11. Kiehl, J.T.; Ramanathan, V. Comparison of cloud forcing derived from the Earth Radiation Budget Experiment with that simulated by the NCAR community climate model. J. Geophys. Res. 1990, 95, 11679-11698. [CrossRef]

12. Cess, R.D. Intercomparison and interpretation of climate feedback processes in 19 atmospheric general circulation models. J. Geophys. Res. 1990, 95, 16601-16615. [CrossRef]

13. Hansen, J.E.; Sato, M.; Lacis, A.; Ruedy, R.; Tegen, I.; Matthews, E. Climate forcings in the Industrial era. Proc. Natl. Acad. Sci. USA 1998, 95, 12753-12758. [CrossRef] [PubMed]

14. Soden, B.J.; Held, I.M. An assessment of climate feedbacks in coupled ocean-atmospheric models. J. Clim. 2006, 19, 3354-3360. [CrossRef]

15. Jiang, J.H.; Su, H.; Zhai, C.; Perun, V.S.; Del Genio, A.; Nazarenko, L.S.; Donner, L.J.; Horowitz, L.; Seman, C.; Cole, J.; et al. Evaluation of cloud and water vapor simulations in CMIP5 climate models Using NASA "A-Train" satellite observations. J. Geophys. Res. Atmos. 2012, 117, D14105. [CrossRef]

16. Taylor, P.C. The Role of Clouds: An Introduction and Rapporteur Report. Surv. Geophys. 2012, 33, 609-617. [CrossRef]

17. IPCC. Climate Change 2014: Synthesis Report. Contribution of Working Groups I, II and III to the Fifth Assessment Report of the Intergovernmental Panel on Climate Change; IPCC: Geneve, Switzerland, 2014; ISBN 9789291691432.

18. Ignatov, A.; Minnis, P.; Loeb, N.; Wielicki, B.; Miller, W.; Sun-Mack, S.; Tanré, D.; Remer, L.; Laszlo, I.; Geier, E. Two MODIS aerosol products over ocean on the Terra and Aqua CERES SSF datasets. J. Atmos. Sci. 2005, 62, 1008-1031. [CrossRef]

19. Kaufman, Y.J.; Koren, I.; Remer, L.A.; Rosenfeld, D.; Rudich, Y. The effect of smoke, dust, and pollution aerosol on shallow cloud development over the Atlantic Ocean. Proc. Natl. Acad. Sci. USA 2005, 102, 11207-11212. [CrossRef]

20. Loeb, N.G.; Manalo-Smith, N. Top-of-atmosphere direct radiative effect of aerosols over global oceans from merged CERES and MODIS observations. J. Clim. 2005, 18, 3506-3526. [CrossRef]

21. Matheson, M.A.; Coakley, J.A.; Tahnk, W.R. Multiyear Advanced Very High Resolution Radiometer observations of summertime stratocumulus collocated with aerosols in the northeastern Atlantic. J. Geophys. Res. Atmos. 2006, 111. [CrossRef] 
22. Koren, I.; Vanderlei Martins, J.; Remer, L.A.; Afargan, H. Smoke invigoration versus inhibition of clouds over the amazon. Science 2008, 321, 946-949. [CrossRef] [PubMed]

23. Koren, I.; Kaufman, Y.J.; Rosenfeld, D.; Remer, L.A.; Rudich, Y. Aerosol invigoration and restructuring of Atlantic convective clouds. Geophys. Res. Lett. 2005, 32. [CrossRef]

24. Koren, I.; Feingold, G.; Remer, L.A. The invigoration of deep convective clouds over the Atlantic: Aerosol effect, meteorology or retrieval artifact? Atmos. Chem. Phys. 2010, 10, 8855-8872. [CrossRef]

25. Yuan, T.; Remer, L.A.; Yu, H. Microphysical, macrophysical and radiative signatures of volcanic aerosols in trade wind cumulus observed by the A-Train. Atmos. Chem. Phys. 2011, 11, 7119-7132. [CrossRef]

26. Andreae, M.O.; Rosenfeld, D.; Artaxo, P.; Costa, A.A.; Frank, G.P.; Longo, K.M.; Silva-Dias, M.A.F. Smoking Rain Clouds over the Amazon. Science 2004, 103, 32141-32157. [CrossRef] [PubMed]

27. Bell, T.L.; Rosenfeld, D.; Kim, K.M.; Yoo, J.M.; Lee, M.I.; Hahnenberger, M. Midweek increase in U.S. summer rain and storm heights suggests air pollution invigorates rainstorms. J. Geophys. Res. Atmos. 2008, 113. [CrossRef]

28. Jiang, J.H.; Su, H.; Huang, L.; Wang, Y.; Massie, S.; Zhao, B.; Omar, A.; Wang, Z. Contrasting effects on deep convective clouds by different types of aerosols. Nat. Commun. 2018, 9. [CrossRef]

29. Khain, A.; Rosenfeld, D.; Pokrovsky, A. Aerosol impact on the dynamics and microphysics of deep convective clouds. Q. J. R. Meteorol. Soc. 2005, 131, 2639-2663. [CrossRef]

30. Lin, J.C.; Matsui, T.; Pielke, S.A.; Kummerow, C. Effects of biomass-burning-derived aerosols on precipitations and clouds in the Amazon Basin: A satellite-based empirical study. J. Geophys. Res. Atmos. 2006. [CrossRef]

31. Niu, F.; Li, Z. Systematic variations of cloud top temperature and precipitation rate with aerosols over the global tropics. Atmos. Chem. Phys. 2012, 12, 8491-8498. [CrossRef]

32. Massie, S.T.; Heymsfield, A.; Schmitt, C.; Müller, D.; Seifert, P. Aerosol indirect effects as a function of cloud top pressure. J. Geophys. Res. Atmos. 2007. [CrossRef]

33. Wonsick, M.M.; Pinker, R.T.; Govaerts, Y. Cloud variability over the Indian monsoon region as observed from satellites. J. Appl. Meteorol. Climatol. 2009, 48, 1803-1821. [CrossRef]

34. Shang, H.; Letu, H.; Nakajima, T.Y.; Wang, Z.; Ma, R.; Wang, T.; Lei, Y.; Ji, D.; Li, S.; Shi, J. Diurnal cycle and seasonal variation of cloud cover over the Tibetan Plateau as determined from Himawari-8 new-generation geostationary satellite data. Sci. Rep. 2018. [CrossRef] [PubMed]

35. Katti, V.R.; Pratap, V.R.; Dave, R.K.; Mankad, K.N. INSAT-3D: An advanced meteorological mission over Indian Ocean. GEOSS Next Gen. Sens. Mission. 2006, 6407, 640709.

36. Winker, D.M.; Vaughan, M.A.; Omar, A.; Hu, Y.; Powell, K.A.; Liu, Z.; Hunt, W.H.; Young, S.A. Overview of the CALIPSO mission and CALIOP data processing algorithms. J. Atmos. Ocean. Technol. 2009, 26, 2310-2323. [CrossRef]

37. Sassen, K.; Wang, Z.; Liu, D. Global distribution of cirrus clouds from CloudSat/Cloud-Aerosol Lidar and Infrared Pathfinder Satellite Observations (CALIPSO) measurements. J. Geophys. Res. 2008, 113, D00A12. [CrossRef]

38. Sassen, K.; Wang, Z.; Liu, D. Cirrus clouds and deep convection in the tropics: Insights from CALIPSO and CloudSat. J. Geophys. Res. Atmos. 2009, 114, 1-11. [CrossRef]

39. Chung, C.Y.; Francis, P.N.; Saunders, R.W.; Kim, J. Comparison of SEVIRI-derived cloud occurrence frequency and cloud-top height with a-train data. Remote Sens. 2017, 9, 24. [CrossRef]

40. Stengel, M.; Mieruch, S.; Jerg, M.; Karlsson, K.G.; Scheirer, R.; Maddux, B.; Meirink, J.F.; Poulsen, C.; Siddans, R.; Walther, A.; et al. The Clouds Climate Change Initiative: Assessment of state-of-the-art cloud property retrieval schemes applied to AVHRR heritage measurements. Remote Sens. Environ. 2015, 162, 363-379. [CrossRef]

41. Qin, Y.; Steven, A.D.L.; Schroeder, T.; McVicar, T.R.; Huang, J.; Cope, M.; Zhou, S. Cloud cover in the Australian region: Development and validation of a cloud masking, classification and optical depth retrieval algorithm for the advanced Himawari imager. Front. Environ. Sci. 2019, 7. [CrossRef]

42. Liu, Z.; Vaughan, M.; Winker, D.; Kittaka, C.; Getzewich, B.; Kuehn, R.; Omar, A.; Powell, K.; Trepte, C.; Hostetler, C. The CALIPSO lidar cloud and aerosol discrimination: Version 2 algorithm and initial assessment of performance. J. Atmos. Ocean. Technol. 2009. [CrossRef]

43. Getzewich, B.J.; Vaughan, M.A.; Hunt, W.H.; Avery, M.A.; Powell, K.A.; Tackett, J.L.; Winker, D.M.; Kar, J.; Lee, K.P.; Toth, T.D. CALIPSO lidar calibration at $532 \mathrm{~nm}$ : Version 4 daytime algorithm. Atmos. Meas. Tech. 2018, 11, 6309-6323. [CrossRef] 
44. Kar, J.; Vaughan, M.A.; Lee, K.P.; Tackett, J.L.; Avery, M.A.; Garnier, A.; Getzewich, B.J.; Hunt, W.H.; Josset, D.; Liu, Z.; et al. CALIPSO lidar calibration at $532 \mathrm{~nm}$ : Version 4 nighttime algorithm. Atmos. Meas. Tech. 2018, 11, 1459-1479. [CrossRef]

45. Barnes, W.L.; Pagano, T.S.; Salomonson, V. V Prelaunch Characteristics of the Moderate Resolution. IEEE Trans. Geosci. Remote Sens. 1998, 36, 1088-1100. [CrossRef]

46. Guenther, B.; Godden, G.D.; Xiong, X.; Knight, E.J.; Qiu, S.-Y.; Montgomery, H.; Hopkins, M.M.; Khayat, M.G.; Hao, Z. Prelaunch algorithm and data format for the Level 1 calibration products for the EOS-AM1 Moderate Resolution Imaging Spectroradiometer (MODIS). IEEE Trans. Geosci. Remote Sens. 1998, 36, 1142-1151. [CrossRef]

47. Ackerman, S.; Strabala, K.I.; Menzel, W.P.; Frey, R.A.; Moeller, C.C.; Gumley, L.E. Discriminating clear sky from clouds with MODIS. J. Geophys. Res. 1998, 103, 32141-32157. [CrossRef]

48. Platnick, S.; King, M.D.; Ackerman, S.A.; Menzel, W.P.; Baum, B.A.; Riédi, J.C.; Frey, R.A. The MODIS cloud products: Algorithms and examples from terra. IEEE Trans. Geosci. Remote Sens. 2003, 41, 459-473. [CrossRef]

49. Derrien, M.; Le Gléau, H. MSG/SEVIRI cloud mask and type from SAFNWC. Int. J. Remote Sens. 2005, 26, 4707-4732. [CrossRef]

50. Dybbroe, A.; Karlsson, K.-G.; Thoss, A. NWCSAF AVHRR Cloud Detection and Analysis Using Dynamic Thresholds and Radiative Transfer Modeling. Part I: Algorithm Description. J. Appl. Meteorol. 2005, 44, 39-54. [CrossRef]

51. Choi, Y.; Ho, C. Validation of cloud property retrievals from MTSAT-1R imagery using MODIS observations. Int. J. Remote Sens. 2009, 30, 5935-5958. [CrossRef]

52. Frey, R.A.; Ackerman, S.A.; Liu, Y.; Strabala, K.I.; Zhang, H.; Key, J.R.; Wang, X. Cloud detection with MODIS. Part I: Improvements in the MODIS cloud mask for Collection 5. J. Atmos. Ocean. Technol. 2008, 25, 1057-1072. [CrossRef]

53. Rossow, W.B.; Garder, L.C. Cloud detection using satellite measurements of infrared and visible radiances for ISCCP. J. Clim. 1993, 6, 2341-2369. [CrossRef]

54. Hunt, G.E. Radiative properties of terrestrial clouds at visible and infra-red thermal window wavelengths. Q. J. R. Meteorol. Soc. 1973, 99, 346-369. [CrossRef]

55. Jedlovec, G.J.; Haines, S.L.; LaFontaine, F.J. Spatial and Temporal Varying Thresholds for Cloud Detection in GOES Imagery. IEEE Trans. Geosci. Remote Sens. 2008, 46, 1705-1717. [CrossRef]

56. Coakley, J.A.; Bretherton, F.P. Cloud cover from high-resolution scanner data: Detecting and allowing for partially filled fields of view. J. Geophys. Res. 1982, 87, 4917. [CrossRef]

57. Borgne, P.L.; Legendre, G.; Marsouin, A. Ocean and sea ice SAF Product from MSG data. In Proceedings of the EUMETSAT Meteorological Satellite Conference, Weimar, Germany, 29 September-3 October 2003; pp. 512-519.

58. Shang, H.; Chen, L.; Letu, H.; Zhao, M.; Li, S.; Bao, S. Development of a daytime cloud and haze detection algorithm for Himawari-8 satellite measurements over central and eastern China. J. Geophys. Res. 2017. [CrossRef]

59. Berendes, T.A.; Kuo, K.S.; Logar, A.M.; Corwin, E.M.; Welch, R.M.; Baum, B.A.; Pretre, A.; Weger, R.C. A comparison of paired histogram, maximum likelihood, class elimination, and neural network approaches for daylight global cloud classification using AVHRR imagery. J. Geophys. Res. Atmos. 1999, 104, 6199-6213. [CrossRef]

60. Platt, C.M.R.; Stephens, G.L. The interpretation of remotely sensed high cloud emittance. J. Atmos. Sci. 1980, 37, 2314-2322. [CrossRef]

61. Inoue, T. On the Temperature Measurements and Effective Cirrus Emissivity Clouds by Window Determination Region of Semi-Transparent in the. J. Meteorol. Soc. Jpn. 1985, 63, 88-99. [CrossRef]

62. Inoue, T. A cloud type classification with NOAA 7 split-window measurements. J. Geophys. Res. 1987, 92, 3991-4000. [CrossRef]

63. Roca, R.; Viollier, M.; Picon, L.; Desbois, M. A multisatellite analysis of deep convection and its moist environment over the Indian Ocean during the winter monsoon. J. Geophys. Res. Atmos. 2002, 107. [CrossRef]

64. Rajeev, K.; Parameswaran, K.; Meenu, S.; Sunilkumar, S.V.; Thampi, B.V.; Raju, C.S.; Murthy, B.V.K.; Jagannath, K.S.; Mehta, S.K.; Rao, D.N.; et al. Observational assessment of the potential of satellite-based 
water vapor and thermal IR brightness temperatures in detecting semitransparent cirrus. Geophys. Res. Lett. 2008, 35. [CrossRef]

65. Wu, M.-L.C. A method for remote sensing emissivity, fractional cloud cover and cloud top temperature of high level, thin clouds. J. Clim. Appl. Meteorol. 1987, 26, 225-233. [CrossRef]

66. Korpela, A.; Dybbroe, A.; Thoss, A. Nowcasting SAF- Retrieving Cloud Top Temperature and Height in Semi-Transparent and Fractional Cloudiness Using AVHRR. Reports Meteorol. 100. 2001. Available online: https://www.smhi.se/polopoly_fs/1.139622!/Meteorologi_100.pdf (accessed on 16 November 2019).

67. NASA: CALIPSO. Data User's Guide-Data Product Descriptions_Lidar Level 25 km Vertical Feature Mask (VFM) Version 4.10 Product. Available online: https//www-calipso.larc.nasa.gov/resources/calipso_users_ guide/data_summaries/vfm/index_v410.php (accessed on 16 November 2019).

68. Zhang, J.; Chen, H.; Li, Z.; Fan, X.; Peng, L.; Yu, Y.; Cribb, M. Analysis of cloud layer structure in Shouxian, China using RS92 radiosonde aided by 95 GHz cloud radar. J. Geophys. Res. Atmos. 2010, 115, 1-13. [CrossRef]

69. Poore, K.D.; Junhong, W.; Rossow, W.B. Cloud layer thicknesses from a combination of surface and upper-air observations. J. Clim. 1995, 8, 550-568. [CrossRef]

70. Wang, J.; Rossow, W. Determination of Cloud Vertical Structure from Upper-Air Observations. J. Appl. Meteorol. 1995, 2243-2258. [CrossRef]

71. Costa-Surós, M.; Calbó, J.; González, J.A.; Long, C.N. Comparing the cloud vertical structure derived from several methods based on radiosonde profiles and ground-based remote sensing measurements. Atmos. Meas. Tech. 2014, 7, 2757-2773. [CrossRef]

72. Zhang, J.; Li, Z.; Chen, H.; Cribb, M. Validation of a radiosonde-based cloud layer detection method against a ground-based remote sensing method at multiple arm sites. J. Geophys. Res. Atmos. 2013, 118, 846-858. [CrossRef]

73. Narendra Reddy, N.; Venkat Ratnam, M.; Basha, G.; Ravikiran, V. Cloud vertical structure over a tropical station obtained using long-term high-resolution radiosonde measurements. Atmos. Chem. Phys. 2018, 18, 11709-11727. [CrossRef]

74. Ramana, M.V.; Ramanathan, V. Abrupt transition from natural to anthropogenic aerosol radiative forcing: Observations at the ABC-Maldives Climate Observatory. J. Geophys. Res. Atmos. 2006, 111. [CrossRef]

75. Benas, N.; Finkensieper, S.; Stengel, M.; Van Zadelhoff, G.J.; Hanschmann, T.; Hollmann, R.; Meirink, J.F. The MSG-SEVIRI-based cloud property data record CLAAS-2. Earth Syst. Sci. Data 2017, 9, 415-434. [CrossRef]

76. Stengel, M.; Stapelberg, S.; Sus, O.; Schlundt, C.; Poulsen, C.; Thomas, G.; Christensen, M.; Henken, C.C.; Preusker, R.; Fischer, J.; et al. Cloud property datasets retrieved from AVHRR, MODIS, AATSR and MERIS in the framework of the Cloud-cci project. Earth Syst. Sci. Data 2017, 9, 881-904. [CrossRef]

77. Wielicki, B.A.; Parker, L. On the determination of cloud cover from satellite sensors: The effect of sensor spatial resolution. J. Geophys. Res. 1992, 97, 12799-12823. [CrossRef]

78. Chan, M.A.; Comiso, J.C. Cloud features detected by MODIS but not by CloudSat and CALIOP. Geophys. Res. Lett. 2011, 38. [CrossRef]

79. Kahn, B.H.; Chahine, M.T.; Stephens, G.L.; Mace, G.G.; Marchand, R.T.; Wang, Z.; Barnet, C.D.; Eldering, A.; Holz, R.E.; Kuehn, R.E.; et al. Cloud type comparisons of AIRS, CloudSat, and CALIPSO cloud height and amount. Atmos. Chem. Phys. 2008, 8, 1231-1248. [CrossRef]

80. Ackerman, S.; Frey, R.; Strabala, K.; Liu, Y.; Gumley, L.; Baum, B.; Menzel, P. Discriminating Clear-Sky from Cloud with MODIS Algorithm Theoretical Basis Document (MOD35); 2010. Available online: https: //modis-images.gsfc.nasa.gov/_docs/MOD35_ATBD_Collection6.pdf (accessed on 16 November 2019).

81. Wang, T.; Fetzer, E.J.; Wong, S.; Kahn, B.H.; Yue, Q. Validation of MODIS cloud mask and multilayer flag using CloudSat-CALIPSO cloud profiles and a cross-reference of their cloud classifications. J. Geophys. Res. 2016. [CrossRef]

82. Hanna, J.W.; Schultz, D.M.; Irving, A.R. Cloud-top temperatures for precipitating winter clouds. J. Appl. Meteorol. Climatol. 2008, 47, 351-359. [CrossRef]

83. Sherwood, S.C.; Chae, J.H.; Minnis, P.; McGill, M. Underestimation of deep convective cloud tops by thermal imagery. Geophys. Res. Lett. 2004. [CrossRef]

84. Gelaro, R.; McCarty, W.; Suárez, M.J.; Todling, R.; Molod, A.; Takacs, L.; Randles, C.A.; Darmenov, A.; Bosilovich, M.G.; Reichle, R.; et al. The modern-era retrospective analysis for research and applications, version 2 (MERRA-2). J. Clim. 2017, 30, 5419-5454. [CrossRef] 
85. Huang, Y.; Siems, S.; Manton, M.; Protat, A.; Majewski, L.; Nguyen, H. Evaluating Himawari-8 Cloud Products Using Shipborne and CALIPSO Observations: Cloud-top Height and Cloud-top Temperature. J. Atmos. Ocean. Technol. 2019. [CrossRef]

86. Taylor, S.; Stier, P.; White, B.; Finkensieper, S.; Stengel, M. Evaluating the diurnal cycle in cloud top temperature from SEVIRI. Atmos. Chem. Phys. 2017, 17, 7035-7053. [CrossRef]

87. Stubenrauch, C.J.; Cros, S.; Guignard, A.; Lamquin, N. A 6-year global cloud climatology from the Atmospheric InfraRed Sounder AIRS and a statistical analysis in synergy with CALIPSO and CloudSat. Atmos. Chem. Phys. 2010, 10, 7197-7214. [CrossRef]

88. Minnis, P.; Yost, C.R.; Sun-Mack, S.; Chen, Y. Estimating the top altitude of optically thick ice clouds from thermal infrared satellite observations using CALIPSO data. Geophys. Res. Lett. 2008. [CrossRef]

89. Stubenrauch, C.J.; Rossow, W.B.; Kinne, S.; Ackerman, S.; Cesana, G.; Chepfer, H.; Di Girolamo, L.; Getzewich, B.; Guignard, A.; Heidinger, A.; et al. Assessment of global cloud datasets from satellites: Project and database initiated by the GEWEX radiation panel. Bull. Am. Meteorol. Soc. 2013. [CrossRef]

90. Hamada, A.; Nishi, N.; Kida, H.; Shiotani, M.; Iwasaki, S.; Kamei, A.; Ohno, Y.; Kuroiwa, H.; Kumagai, H.; Okmoto, H. Cloud type classification by GMS-5 infrared split window measurements with millimeter-wave radar and TRMM observations in the tropics. In Proceedings of the 2nd TRMM International Science Conference, Nara, Japan, 6-10 September 2004.

91. Lutz, H.-J.; Inoue, T.; Schmetz, J. Comparison of a Split-window and a Multi-spectral Cloud Classification for MODIS Observations. J. Meteorol. Soc. Jpn. 2003, 81, 623-631. [CrossRef]

(C) 2019 by the authors. Licensee MDPI, Basel, Switzerland. This article is an open access article distributed under the terms and conditions of the Creative Commons Attribution (CC BY) license (http://creativecommons.org/licenses/by/4.0/). 